\title{
How can the landscape ecological security pattern be quantitatively optimized and effectively evaluated? An integrated analysis with the granularity inverse method and landscape indicators
}

Dongjie Guan ( $\nabla$ guandongjie_2000@163.com )

Chongqing Jiaotong University https://orcid.org/0000-0002-7857-0957

Yanan Jiang

Chongqing Jiaotong University

Lidan Cheng

Chongqing Jiaotong University

\section{Research Article}

Keywords: Landscape ecological security pattern, optimization model, granularity inverse method, minimum cumulative resistance model

Posted Date: May 4th, 2021

DOl: https://doi.org/10.21203/rs.3.rs-455799/v1

License: (9) This work is licensed under a Creative Commons Attribution 4.0 International License. Read Full License

Version of Record: A version of this preprint was published at Environmental Science and Pollution Research on January 30th, 2022. See the published version at https://doi.org/10.1007/s11356-02116759-1. 


\title{
Article
}

\section{How can the landscape ecological security pattern be quantitatively optimized and effectively evaluated? An integrated analysis with the granularity inverse method and landscape indicators}

\author{
Dongjie Guan ${ }^{1 *}$, Yanan Jiang ${ }^{1}$, Lidan Cheng ${ }^{1,2}$ \\ 1 College of Architecture and Urban Planning, Chongqing Jiaotong University, No.66 Xuefu Rd., Nan'an Dist., China \\ ; 1131667091@qq.com \\ 2 Chongqing Geomatics and Remote Sensing Center, Chongqing 401147, China; cldheipingguo@163.com \\ * Correspondence: guandongjie_2000@163.com; Tel.: +185-0238-8076
}

\begin{abstract}
The optimization of the landscape ecological security pattern aims to construct a suitable ecological environment and promote the harmonious development between humans and nature. The optimization model of the ecological security pattern for the main urban area of Chongqing was constructed with the granularity inverse method, minimum cumulative resistance model, and spatial network analysis method. We used ecological nodes to optimize the landscape ecological security pattern by organically combining the landscape quantity and spatial structure. The results were as follows: (1) The optimal granularity for selecting the ecological source in the study area was $500 \mathrm{~m}$. There were 220 ecological sources with a total area of $188691.03 \mathrm{hm}^{2}$ and a minimum area of $75.15 \mathrm{hm}^{2}$. (2) The ecological buffer zone, protection and utilization zone, key development zone, coordinated control zone, and restricted development zone accounted for $57.78 \%$, $20.87 \%, 12.36 \%, 6.48 \%$ and $2.50 \%$, respectively, of the total area. (3) The constructed of the landscape ecological security pattern contained 70 ecological corridors with a total length of $415.89 \mathrm{~km}$. The longest and shortest ecological corridors had lengths of $20.33 \mathrm{~km}$ and $1153.23 \mathrm{~m}$, respectively. There were 17 ecological nodes of corridor-resistance and 27 ecological nodes of corridor-corridor. (4) 41 ecological node service areas were constructed, with a total area of approximately $236.0723 \mathrm{hm}^{2}$, accounting for $0.04 \%$ of the total study area, and the largest and smallest ecological node areas were $6.0744 \mathrm{hm}^{2}$ and $0.0057 \mathrm{hm}^{2}$, respectively. (5) The optimized result of the landscape ecological security pattern converted $209.1384 \mathrm{hm}^{2}$ of nonecological land into ecological land.
\end{abstract}

Keywords Landscape ecological security pattern $\cdot$ optimization model $\cdot$ granularity inverse method $\cdot$ minimum cumulative resistance model

\section{Introduction}

Ecological security refers to the normal operation of the ecosystem in a specific region, the sound development and supply-demand balance of the environment, resources and human security in the ecosystem, and the social situation with human beings as the main body is not threatened by the external factors (Falkmark 2002; Folke 2002; Molden 2002; Geoffrey and Matthews 2002; Rajagopal 2002; Sendama and Granit 2002). It may provide guarantee for the complete ecological function and sustainability of an eco-economic system (Gao 2017) and provides a direction for sustainable natural environment development (Yu 1996; Opdam et al. 2006), which emphasizes the balance between nature and ecology under the premise of human survival. It is difficult to achieve ecological security, which involves all aspects of society, economy and natural ecology. However, the construction of ecological security patterns focuses on solving specific ecological problems, which is a quantifiable ecological practice method. The construction of ecological security patterns can be applied in urban ecological environment planning through practical applications. 
The landscape ecology theory holds that there is a certain potential ecosystem spatial pattern in the landscape (Mayer et al. 2016; Turner 2005). It is composed of key parts of the landscape, and its orientation and spatial relationship are combined to form a landscape ecological security pattern (LESP) (Mo et al. 2017). The landscape ecological pattern reflects the ecological process of the regional landscape and has an important improvement or degradation significance for these processes (Mayer et al. 2016; Abdullah and Nakagoshi 2006, 2008; Opdam et al. 2006). Different landscape ecological patterns have different responses to the improvement or degradation of ecological processes (López et al. 2020).

The LESP provides important information for ecological protection and management. It can reveal the spatial distribution and concentration characteristics of landscape factors. Therefore, LESP studies should not only consider landscape patterns and processes but should also consider the impact of landscape factors reflecting the landscape structure and function on the ecological security (Zhao and Xu 2015).

The LESP is an important way to identify conservation and strengthen connectivity and management effectiveness on a regional scale. According to the feedback of landscape patterns and ecological processes, existing research shows that optimizing LESP is an effective way to support biological species, maintain natural ecological processes, improve regional ecological security, and achieve ecological security (Li et al. 2020; Peng 2018).

With the increasing development of landscape ecological planning research, LESP optimization started in the 1980s, and an independent ideology on the LESP was formed. LESP optimization aims to construct a scientific optimization spatial structure and ecological network with a practical guiding significance for protecting the ecological environment and promoting regional coordinated development. Currently, the graph theory and spatial simulation methods are adopted in the field of LESP optimization to realize its research objectives (Li et al. 2010; Yu et al. 2018; Monaco et al. 2020).

At present, LESP optimization in many studies has focused on the construction of optimization models and standards. It is commonly accepted that the model of ecological source - resistance surface-ecological corridors and nodes (Zhao et al. 2019; Yu et al. 1996) can construct the LESP (Yu 2017). However, different scholars tend to select different methods for identifying the ecological sources and ecological resistance surfaces. For example, Peng et al. (2018) used ecosystem services to identify the ecological sources and adopted the circuit theory to model the ecosystem processes in heterogeneous landscapes by calculating the resistance or current and to thusly identify ecological corridors and key ecological nodes. Wang and Pan (2019) extracted ecological sources and corridors at three safety levels to form corresponding ESPs with the source-sink theory of landscape ecology, minimum cumulative resistance model, and geographic information system techniques. Peng et al. (2019) applied the ant colony algorithm and kernel density estimation to identify the range and restoration points of ecological corridors. Su et al. (2019) identified ecological sources through ecosystem importance assessment and adopted the interaction force theory to model ecosystem processes.

Optimization standard identification is also highly effective for constructing and simulating LESP; it includes ecosystem services, ecological land, ecological risk, ecological factors and socioeconomic conditions, in addition to an evaluation indicator and an integrated framework (Xie et al. 2015). However, different scholars tend to select different indicators and quantities, and a single standard is lacking. For example, Chang et al. (2011) attempted to integrate ecological factors and socioeconomic conditions via landscape function modeling and network analysis to establish strategies for ULP design. Sunderland et al. (2017) applied detailed socioecological methodologies in multifunctional landscapes and assessed the subsequent implications for conservation, livelihood and food security. Ma et al. (2019) calculated the correlation and correlation coefficients between the ecological security and landscape pattern of the study region to provide useful information for ecological regulation and design. Peng et al. (2017) characterized the ecological land dynamics in Shenzhen city and quantified the driving forces using multivariate logistic regression and subsequently mapped the transition probability of ecological land for decision making in the construction of urban LESP. Li et al. (2020) presented an integrated framework for identifying, analyzing, and optimizing ESPs considering the core area extracted based on morphological spatial pattern analysis (MSPA), ecosystem services importance, and ecological risk indicator. Lu et al. (2020) proposed an evaluation indicator system for measuring the forest ecological security indicator (FESI).

Despite the rich research on LESP optimization model construction and optimization standard identification, the following two essential aspects have been less commonly studied over the long term: (1) the determination of important thresholds for constructing LESP is wanting (Desmet 2018), especially because the granularity threshold of ecological sources remains unclear and the shape and the scale threshold of ecological 
nodes is lacking (Zhao et al. 2019; Mõisja and Uuemaa 2016; Weber et al. 2006); (2) many studies have constructed corresponding ecological security patterns based on different standards, different ecological protection goals or different security pattern levels; however, effectiveness and rationality evaluation after LESP optimization is deficient, especially because quantitative evaluation and indicator evaluation are missing (Jim and Chen 2003; Pili et al. 2019).

Urban planning should play a leading role during the process of civilization construction, which should drive urban development, adjust the urban spatial structure, and plan the urban ecological land layout (Wang et al. 2015). Chongqing's main urban area is situated in the core strategic area of Chongqing, China, which is in urgent need of scientific and effective planning and guidance. Against this background, our objective is to construct LESP for Chongqing's main urban area considering the granularity threshold of ecological sources and the shape and scale thresholds of ecological nodes. We employ the landscape indicator method to perform a quantitative evaluation to verify the effectiveness and rationality of the optimized LESP to verify the applicability and operability of the optimized LESP. Our research can serve as a valuable reference for promoting a new urbanization development plan for Chongqing, China, and offers important implications for improving landscape sustainability sciences.

\section{Study area and data}

\subsection{Study area}

The main urban area of Chongqing is located at $106^{\circ} 12^{\prime}-106^{\circ} 59^{\prime} \mathrm{E}$ longitude and $29^{\circ} 7^{\prime}-30^{\circ} 7^{\prime} \mathrm{N}$ latitude and covers $5466 \mathrm{~km}^{2}$, accounting for $6.6 \%$ of the total area of Chongqing. The main urban area of Chongqing encompasses nine administrative districts (i.e., Yuzhong, Jiangbei, Yubei, Shapingba, Nan'an, Jiulongpo, Dadukou, Banan, and Beibei) (Fig.1). Among them, Yuzhong District, covering an area of $23.71 \mathrm{~km}^{2}$, is the smallest of the nine districts, which hosts the Chongqing municipal government and is the mother city for the economic and cultural development of Chongqing.

\section{$<$ Please insert Fig. 1 about here>}

The altitude of the main urban area of Chongqing ranges from $140 \mathrm{~m}$ to $1327 \mathrm{~m}$, with an average altitude of approximately $425 \mathrm{~m}$. The elevation decreases from north to south. The landform is dominated by hills and low mountains. The river system is mainly composed of the Yangtze River and the Jialing River with 22 secondary rivers. The Jialing River and the Yangtze River meet at Chaotianmen Wharf, flowing from west to east through the city, and the confluence of the main body of water divides the main city into three parts.

\subsection{Data}

Four types of data were used in this study (Table 1): (1) Land use data. The land use data came from the Chongqing Key Laboratory of GIS application research, with spatial resolution of $30 \mathrm{~m}$ and data time of 2015. The selected first-level classification standard of the various land use types includes six categories: cultivated land, forestland, lawn, water area, urban and rural residential areas, industrial and mining area, and unused land, among which the construction land contains urban land, rural residential area and other construction land. (2) Remote sensing data. The remote sensing data mainly relied on the normalized vegetation indicator (NDVI) data of the main urban area of Chongqing. The NDVI data consisted of Terra-MODIS 16-day normalized vegetation indicator synthetic data with a spatial resolution of $250 \mathrm{~m}$, all of which were archived and downloaded from NASA (http://ladsweb.nascom.nasa.gov). (3) Basic geographic information data. The basic geographic information data mainly included digital elevation models (DEMs), ecological red lines, scenic spots, and high-geological disaster and high-risk areas of water, soil and water flow. The DEM data used SRTM1 Arc-Second Global data with a spatial resolution of $30 \mathrm{~m}$ of 2015, from the Shuttle Radar Topography Mission (SRTM) jointly measured by the National Aeronautics and Space Administration (NASA) and National Imagery and Mapping Agency (NIMA). The corresponding download website is https://gdex.cr.usgs.gov/gdex/. The data on the ecological red lines, basic farmland areas, risk areas of soil erosion, scenic areas, green land protection areas, geological disaster-prone areas and other data were obtained from the Chongqing urban and rural master plan (2007-2020) (http://www.cqupb.gov.cn), after registration and 
vectorization, followed by unification to the geographic coordinate system of GCS_WGS_1984 and projection coordinate system of WGS_1984_Albers, and a geographic database was uniformly established. (4) Statistics. The data mainly came from the Chongqing Statistical Yearbook of 2018, which was published by the China Statistical Publishing House and compiled by the Chongqing Municipal Bureau of Statistics and the Chongqing Survey Team of the National Bureau of Statistics. The relevant website is http://www.cqtj.gov.cn/tjnj/2018/zk/index.htm.

$<$ Please insert Table 1 about here $>$

\section{Research methods}

\subsection{The granularity reverse method}

The granularity inversion method is derived from the mathematical disproportion method, which is a method to determine the best ecological source in the construction of landscape ecological security pattern. The research framework is shown in Fig.2. Firstly, a series of ecological landscape indexes are selected, and then the connectivity of the structure and quantity of ecological landscape components under different granularity levels is simulated and analyzed by setting different granularity levels. Then the principal component analysis method is used to determine the optimal ecological landscape component structure. Finally, the original data is regressed to select the ecological source. It is necessary to first assume that there are different ecological source structures in the research area and then determine the existence of unique optimal source structures by inversion. In this study, landscape indicator analysis method was used to calculate the connectivity of these ecological landscape components, and principal component analysis was used to normalize the results. According to the change trend and quality change point reflected by the overall comprehensive score, the spatial structure of the optimal ecological source selection is counter selected to complete the process of ecological source selection. The specific method steps are as follows: firstly, considering the spatial scale, the ecological landscape of Chongqing's main urban area is simulated with different grid sizes in arcgis10.4 software to generate a series of continuous and different ecological landscape component structures; secondly, from the perspective of the integrity and connectivity of the landscape, nine landscape pattern indicators, namely, the number of patch components (NC), patch density (PD), the number of maximum patch components (Max NC), proximity mean distance (PROX_MN), proportion of like adjacencies (PLADJ), connectivity indicator (CONNECT), aggregation indicator (AI), patch cohesion indicator (COHESION) and landscape division indicator (DIVISION), were selected to calculate the landscape component structure at the landscape level. In order to achieve the scale effect and connectivity of landscape pattern, we selected three landscape indices in terms of area, shape and aggregation to analyze the patches (Jia et al. 2018), as shown in the Table 2. Within the scope of landscape research at a specific time, the change of spatial sequence is the comprehensive result of the interaction between landscape patches. The change of a spatial pattern component often leads to the difference of connectivity and mobility of the overall landscape pattern (Wang et al. 2020). The spatial pattern of landscape is not determined by the patch measurement of a single pattern, but by the combination of multiple landscape performance. Therefore, the correlation and interaction between landscape measures should be considered, which is defined as the symbolic effect of spatial pattern components on landscape measurement (Peng et al. 2010). The spatial measurement of landscape pattern can only be determined by selecting different landscape indicators to form the optimal landscape components. In FRAGSTATS software, the quantitative analysis of these ecological landscape component structures was carried out, and the indicator values of ecological landscape components under each granularity were obtained. Then, principal component analysis was carried out in SPSS based on landscape pattern indicator, and 21 landscape component structure indicators were calculated. The overall connectivity was scored by principal components, and the optimal landscape component structure was determined according to the scoring results. Finally, the optimal landscape component structure was determined landscape component structure as a reference, return to the original ecological source data to select part of the ecological source. 


\subsubsection{Setting of the granularity level of the ecological sources}

Ecological land refers to the type of land use that mainly provides ecosystem service functions in regional or urban land areas. Based on the $30 \mathrm{~m}$ resolution data of the main urban areas of Chongqing in 2015, this paper selected forestland, lawn and water area as ecological land, dominated by forest land, accounting for $90.84 \%$ of the total ecological land area, followed by water areas, accounting for $8.52 \%$. Chongqing is a special mountainous city, and its main urban area is also a typical mountainous city. This topographic landform is unsuitable for lawn growth and adaptation, accounting for only $0.64 \%$ of all landforms. The land use map and ecological map of the main urban area of Chongqing are shown in Fig. 3.

\section{$<$ Please insert Fig. 3 about here $>$}

Because the landscape structure of ecological land is composed of forest land, lawn and water area, which are three landscape types under the first-level classification standard of the land use, this paper used the land use data of ecological land to generate landscape component maps with different granularity levels. To ensure the accuracy of subsequent data analysis and ensure its applicability, the principle of granularity setting focused on the range of $50 \mathrm{~m}$ to $1500 \mathrm{~m}$, and the granularity was increased accordingly at 50-m intervals up to a granularity of $600 \mathrm{~m}$, after which the granularity was increased every $100 \mathrm{~m}$, thereby constructing a total of 21 landscape component maps of the ecological sources at different granularity level (Fig. 4).

\section{$<$ Please insert Fig. 4 about here>}

With increasing granularity, the landscape component of the ecological source decreased, and the integrity increased. Because the ecological land in the main urban area of Chongqing runs from north to south and exhibits a relatively uniform strip-like distribution in the east, central and west areas, the core form of the ecosystem did not change much. However, in the process of increasing the granularity, its ecological advantages of the larger ecological patches were expanded, and the surrounding ecological patches were continuously merged to form a larger, while the highly fragmented and smaller ecological patches were gradually eliminated.

\subsubsection{Principal component analysis to determine the best ecological component}

Principal component analysis (PCA) is a multivariate statistical analysis method. Its principle is to select less variables with high importance (retaining original features) from multiple variables through linear transformation or rotation (Liu and Shen 2007; Johnson and Wichern 1998). The core idea of PCA can be expressed as follows: if there are $n$ random variables, they can be expressed as $x_{1}, x_{2}, \ldots, x_{n}$. After standardized processing, the linear combination is carried out according to the data characteristics, and a few new comprehensive variables are obtained to reflect the change characteristics of the data. The formula of comprehensive variable can be expressed as follows:

$$
\begin{gathered}
M_{1}=n_{11} x_{1}+n_{12} x_{2}+n_{13} x_{3}+\ldots \ldots .+n_{1 n} x_{n} \\
M_{m}=n_{m 1} x_{1}+n_{m 2} x_{2}+n_{m 3} x_{3}+\ldots \ldots .+n_{m n} x_{n}
\end{gathered}
$$

Where, $n_{i 1}^{2}+n_{i 2}^{2}+n_{i 3}^{2}+\cdots \ldots+n_{i n}^{2}=1(i=1,2,3, \ldots \ldots, n), M_{i}$ is the weight of the $i^{t h}$ known sample point, and $m$ is the number of known sample points. According to the principal component analysis, the results will get the eigenvector and eigenvalue of the principal component. The proportion of the $i^{\text {th }}$ eigenvalue in the total number is the contribution rate of the main component $M$. In this study, principal component analysis (PCA) was used to calculate 21 landscape component structure indicators. The function expression of principal component analysis is as follows:

$$
\begin{aligned}
& \mathrm{M}_{1}=0.3208 x_{1}+0.3208 x_{2}-0.2697 x_{3}+0.2263 x_{4}+0.3225 x_{5}+0.3358 x_{6}+0.3390 x_{7}+0.1037 x_{8}+0.3215 x_{9} \\
& \mathrm{M}_{2}=0.2916 x_{1}+0.2913 x_{2}-0.0866 x_{3}+0.2419 x_{4}+0.3305 x_{5}+0.2798 x_{6}+0.3349 x_{7}+0.0313 x_{8}+0.3291 x_{9}
\end{aligned}
$$




\subsection{Minimum cumulative resistance model}

The Minimum cumulative resistance model (MCR) model refers to the cost of species moving from "source" to "sink", it was proposed by Knaapen et al. (1992) in 1992 and then applied to the study of two-dimensional spatial expansion of various natural ecological or man-made processes (Evans et al. 2017; Junqueira et al. 2017; Jiang et al. 2019). Because of its simple data structure, good applicability and convenient visualization results, the MCR model was mostly used to evaluate landscape connectivity, optimize landscape ecological security pattern and urban land use planning ( $\mathrm{Li}$ et al. 2015). It's one of the best tools solve the contradictory relation between Human -Land (construction demand-ecological space).

First of all, we evaluated the ecological resistance, which is the cognition of maintaining ecological sustainability and maintaining integrity under various risks in the ecosystem. Refer to Ye et al. (2015) indicator evaluation system for the construction of ecological resistance surface model. Construct the evaluation indicator system of ecological resistance in the main urban area of Chongqing as shown in Table 3, and stipulated the safety level of each constraint factor: $9,7,5,3,1$, respectively representing extremely unsafe, unsafe, low safety, medium and high safety. The smaller the value of the security level, the higher the degree of ecological security and the stronger the ability to resist external interference.

\section{$<$ Please insert Table 3 about here $>$}

Then, we adopted the minimum cumulative resistance model to calculate the minimum cumulative value of the landscape resistance and applied the minimum cumulative resistance surface replace for the ecological operation one. Based on the comprehensive ecological resistance surface of the main urban area of Chongqing, the cost distance according to the ArcGIS 10.4 Cost Distance Tool was used, and the counterselected ecological source area was set as the source, while the comprehensive ecological resistance surface was set as the cost to obtain the minimum cumulative resistance surface of the landscape ecology of the main urban area of Chongqing. The equation of the minimum cumulative resistance model is as follows:

$$
M C R=f \min \sum\left(D_{i j} \times R_{t}\right)(i=1,2, \ldots, n ; j=1,2, \ldots, n)
$$

Where, $D_{i j}$ is the diffusion distance of the species leaving source $j$ through landscape $i, R$ is the resistance of the landscape ${ }^{i}$, and $M C R$ is the minimum cumulative resistance of the species diffusing from source $j$ to a certain point in space. The function $f$ is unknown but reflects the proportional relationship between the material $M C R$ and variable $D_{i j} \times R_{t}$. The resistance $R_{t}$ of each landscape to the spread of a species was determined by the base level characteristics of the landscape and the diffusion ability of the species.

\subsection{Service area analysis method}

Service area is defined as a designated point as the center point, within a certain resistance range, including all areas accessible to the edge. With the designated point as the center point, within a certain resistance range, an area including all accessible edges. In network analysis, the nodes with resources on the network are abstracted as service sites, and the maximum range distance of service sites is abstracted as service radius. After successful analysis, the service network and service area (polygon) of service sites are obtained. Service area analysis as part of spatial network analysis considers the spatial location and accessibility of the network. According to the analysis, the polygonal range of the network can suitably express the dependency relationship between the polygon and the network. This study applied the service area analysis method to calculate the shape and scale of the ecological nodes in the landscape ecological pattern. The steps of calculating the range and shape of the ecological nodes with the service area analysis method in spatial network analysis were as follows: (1) In the process of selecting the inverse of the ecological sources based on the granularity inverse method, the granularity $L$, i.e., the result of the optimal landscape component structure, was used as a reference standard, which calculated the scale for of ecological nodes. (2) According to the majority principle, the formation conditions of ecological nodes states that when the scale of the ecological landscape patch is larger than half the granularity, the ecological node exists as a landscape component. The geometric shape of the ecological node had the characteristics of a circle, and the radius calculation equation of the ecological node is shown in equation (10). (3) The corridor in the 
LESP was the operational network in the network analysis. (4) With the ecological node as the analysis center and $R$ as the analysis radius, the specific scope of the ecological node was determined to obtain the shape and scale of the service area of the ecological node.

$$
R=\sqrt{\frac{L^{2}}{2 \pi}}
$$

$L$ is the granularity, which is the result of the optimal landscape component structure, and is the standard for calculating the scale of ecological nodes; $R$ is the analysis radius.

\subsection{Evaluation indicator establishment after optimization}

Through the calculation of landscape pattern indicator, the results of landscape ecological security pattern of Chongqing main urban area after optimization were evaluated. In this study, the indicator of patch type level indicator and landscape level indicator were selected for quantitative analysis (Table 4), the indicator of patch type level includes patch area ratio(P), patch density (PD), maximum patch indicator (LPI), landscape shape indicator(LSI), fractal dimension(FEAC); the indicator of landscape type level includes Shannon diversity indicator(SHDI), Shannon evenness indicator(SHDI) and landscape connectivity indicator(CONTAG).

\section{$<$ Please insert Table 4 about here $>$}

\section{Results}

\subsection{Determination of the best ecological source}

\subsubsection{The Results of different granularities of ecological land}

The landscape indicator calculation results for the 21 groups of different granularities of ecological land are listed in Table 5.

\section{$<$ Please insert Table 5 about here $>$}

According to the results, a statistical scatter plot of the single-landscape indicator was generated, as shown in Fig. 5. It can be intuitively observed that under the single-landscape indicator, the landscape indicator value changes with increasing granularity.

\section{<Please insert Fig. 5 about here>}

NC decreased sharply from more than $4000 \mathrm{~m}$ to less than $1000 \mathrm{~m}$ when the granularity increased to $300 \mathrm{~m}$ and then gradually decreased to less than 250 landscape components from $300 \mathrm{~m}$ to $1500 \mathrm{~m}$, and $300 \mathrm{~m}$ was the qualitative change point for NC. The change trend of PD was similar to that of the landscape components, and $300 \mathrm{~m}$ was also the qualitative change point, while PD first decreased sharply before this point and then slowly thereafter. The overall density decreased from nearly 2 to nearly 0 . Max NC generally exhibited a fluctuating upward trend, reaching its highest value at a granularity of $500 \mathrm{~m}$, and Max NC approached 80. The trend of PROX_MN was similar to that of NC and PD, and $300 \mathrm{~m}$ again represented the qualitative change point, and the overall value decreased from more than 6000 to close to 0 . The proportion of like adjacencies generally exhibited a uniform downward trend, from less than $90 \%$ to approximately $45 \%$, but the qualitative change point was still $300 \mathrm{~m}$. The connectivity indicator exhibited a fluctuating upward trend before $600 \mathrm{~m}$, reached a peak of approximately 0.6 , decreased abruptly thereafter, and became randomized after $800 \mathrm{~m}$. The cohesion indicator generally exhibited a fluctuating decrease trend, which was basically divided into two segments before and after the qualitative change point. The qualitative change point was $500 \mathrm{~m}$, and the overall cohesion value 
decreased from less than 1 to approximately $94 \%$. The DIVISION indicator exhibited a W-shaped fluctuation trend in the middle section and reached its lowest value at $550 \mathrm{~m}$. The trend of the aggregation indicator was similar to the trend of PLADJ and is not described again.

\subsubsection{The results of principal component analysis to determine the best ecological component}

According to the above single landscape indicator, we calculated the comprehensive score of landscape component structure of ecological source areas under each granularity (Fig. 6), so as to select the optimal landscape component structure and provide reference for scientific and objective selection of ecological source areas.

\section{<Please insert Fig. 6 about here>}

The overall trend of the score was as follows: with increasing granularity to $450 \mathrm{~m}$, the comprehensive score sharply decreased and there was a qualitative change point at $500 \mathrm{~m}$. The comprehensive score increased slightly and then slowly and steadily decreased thereafter to its lowest value. As the granularity continued to increase, small ecological patches were gradually eliminated and became merged, which enhanced the stability of the landscape component structure and decreased fragmentation.

The granularity level of $500 \mathrm{~m}$ was the qualitative change point in the landscape component structure, and its integrity was the best, while the left and right sides of this point exhibited a downward trend in the comprehensive score, indicating the optimal landscape component structure of the ecological source. Finally, $500 \mathrm{~m}$ was adopted as the optimal granularity to determine the ecological sources.

At a granularity of $500 \mathrm{~m}$, the corresponding number of ecological patch components was 568 , which indicated that there are 568 ecological sources in the main urban area of Chongqing with a decisive role in the ecosystem process.

Based on the optimal ecological patch components and sorting according to the size of the ecological patch area, the ecological area of the smallest ecological patch (No. 568) was the smallest ecological source of the research area. Therefore, the ecological source area should be larger than $75 \mathrm{hm}^{2}$, and the ecological patches with corresponding areas larger than $75 \mathrm{hm}^{2}$ should be chosen as the ecological sources of the main urban area of Chongqing. We extracted the raster data of the landscape ecological component structure at a granularity of $500 \mathrm{~m}$ into ArcGIS10.4, and the ecological patches were converted into ecological source areas with conversion and intersection tools, eventually establishing the optimal ecological source structure of the main urban area of Chongqing. According to the spatial distribution of the ecological sources, a total of 220 ecological sources were identified, as shown in Fig.7.

\section{$<$ Please insert Fig. 7 about here>}

The number of ecological sources in the main urban area of Chongqing was large and there were large scale differences. The number of ecological sources was 220 , with a total area of $188691.03 \mathrm{hm}^{2}$. Among them, the largest ecological source area covered $24257.07 \mathrm{hm}^{2}$, accounting for approximately $12.86 \%$ of the total ecological source area. It is located in the northern part of the main urban area of Chongqing and is part of the forest land area connecting Zhongliang Mountain and Longwangdong Mountain. The source area often plays a leading role in maintaining regional ecological security and ecological processes. Ecological source areas should be protected and constructed, and enhanced measures such as buffer zones should be adopted to promote their ecological services. The smallest ecological source area covered $75.15 \mathrm{hm}^{2}$, accounting for approximately $0.04 \%$ of the total ecological source area. It is a small-scale ecological patch that may impose a major impact on the ecosystem of the main urban area of Chongqing. The scale of the subsequent constructed new ecological sources should be considered.

\subsection{Optimization of the landscape ecological security pattern}

\subsubsection{Single-factor and comprehensive evaluation of the ecological resistance}


Based on the spatial data of the ecological resistance in the study area, single-element distribution maps of the ecological resistance were generated in five aspects, i.e., terrain slope, vegetation cover, land cover, ecological sensitivity, and ecological importance, as shown in Fig. 8.

\section{<Please insert Fig. 8 about here>}

The ecological safety of the ecological source areas was comprehensively evaluated by combining GIS spatially weighted superposition analysis technology and the comprehensive indicator method. According to the indicator weights in Table 4, the raster calculator was applied to analyze the resistance value of the ecological resistance factors in the five categories, and the comprehensive ecological resistance surface of the main urban area of Chongqing was obtained. The comprehensive ecological resistance surface is shown in Fig. 9 a.

\section{<Please insert Fig. 9 about here>}

The minimum cumulative resistance surface of the landscape ecology of the main urban area of Chongqing is shown in Fig. 9b.

The area with a low resistance value was the ecological source and its periphery. As the distance from the ecological source increased, the minimum cumulative resistance value of the landscape ecology gradually increased, and the resistance value reached its maximum in the most well-developed regions of the main city.

The minimum cumulative consumption distance surface of the landscape ecology was divided into five grades according to the natural fracture method (Fig. 10), namely, an extremely low-resistance zone, a low-resistance zone, a moderate-resistance zone, while a high-resistance zone and a extremely high-resistance zone.

\section{<Please insert Fig. 10 about here>}

The ecological buffer zone is the extremely low-resistance zone, covering an area of $313073.46 \mathrm{hm}^{2}$, accounting for $57.78 \%$ of the total area. The conservation and utilization zone is the relatively low-resistance zone, covering an area of $113099.13 \mathrm{hm}^{2}$, accounting for $20.87 \%$ of the total area. The key development zone is the moderate-resistance zone, covering an area of $66953.88 \mathrm{hm}^{2}$, accounting for $12.36 \%$ of the total area. The coordinated control zone is the relatively high-resistance zone, covering an area of $35101.26 \mathrm{hm}^{2}$, accounting for $6.48 \%$ of the total area, while the restricted development area, the area with the extremely high-resistance, covers an area of $13569.84 \mathrm{hm}^{2}$, accounting for $2.50 \%$ of the total area.

In this paper, the minimum cumulative resistance surface was adopted as the cost surface operating the ecological flow, utilizing the idea of hydrological analysis to identify the ecological corridors (Beier and Noss, 1998). First, we filled the depressions, calculated the flow direction across depression-free and calculated the cumulative confluence amount. Then, we repeatedly adjusted the threshold, thereby extracting portions of the confluence greater than 1500 to obtain a series of operations just like the river network and determined the valley region and performed vectorization and smoothing. Finally, the least-resistance path in terms of the ecological flow in the study area was obtained, and the path connecting the various ecological sources is the ecological corridor.

Generally, there was certain distance between the various ecological sources in the regional space, which should be connected by the ecological corridor. The ecological nodes occurred at the most vulnerable links of the ecological corridor, namely, the intersection of the ecological corridor and the path with the highest ecological resistance. Similarly, with the minimum cumulative consumption resistance surface as the cost surface of the ecological flow operation, the ridge line on the ecological operation surface was determined with the use of the hydrologic analysis module, and the ridge line location is the position with the highest resistance to the ecological process. The ecological corridor was superimposed on the ridge line, and the corresponding ecological node was determined according to the intersection of the ridge line and the ecological corridor. Hence, the corridor-resistance ecological node was thus generated, and the intersection of the corridor with 
itself was considered the corridor-corridor ecological node. The LESP of the main urban area of Chongqing is shown in Fig. 11.

\section{<Please insert Fig. 11 about here>}

The LESP of the main urban area of Chongqing reveals that there were 220 patches in the ecological source area, with a total area of $188691.03 \mathrm{hm}^{2}$. The largest ecological source covered an area of $24257.07 \mathrm{hm}^{2}$, accounting for $12.86 \%$ of the total ecological source area. It was located in the northernmost part of the main urban area of Chongqing and was part of the forest land. The total number of ecological corridors was 70, and the total length was $415.89 \mathrm{~km}$. The longest corridor was $20.33 \mathrm{~km}$, accounting for $4.89 \%$ of the total length, which was the junction of Zhongliang Mountain and Longwangdong Mountain in the northern section of Chongqing's main urban area. The length of the shortest corridor was $1153.23 \mathrm{~m}$, accounting for approximately $0.28 \%$ of the total length. There were 17 plateau ecological nodes, namely, the ecological nodes of corridor-resistance, and 27 network strategic nodes, namely, the ecological nodes of corridor-corridor.

\subsection{The results of ecological nodes optimization}

The optimal landscape component structure corresponded to a granularity of $500 \mathrm{~m}$, and the radius of the ecological node suitable for the main urban area of Chongqing was calculated with equation (10) as $200 \mathrm{~m}$. With the use of service area analysis as part of spatial network analysis, the detailed shape and size of each ecological node were calculated according to the above steps (Fig. 12).

\section{<Please insert Fig. 12 about here>}

When ecological nodes occurred close to each other, there were overlapping service area, and they were merged into one. The ecological nodes constituted 41 service areas with a total area of approximately 236.0723 $\mathrm{hm}^{2}$, accounting for $0.04 \%$ of the main urban area of Chongqing. Among these nodes, the largest ecological node area was $6.0744 \mathrm{hm}^{2}$, and the smallest ecological node area was $0.0057 \mathrm{hm}^{2}$.

The patches of nonecological land at the ecological nodes were converted into patches of ecological land, and the target landscape types of ecological node construction were forest land, lawn and water area. The principle of landscape conversion was based on the principle of proximity and the principle of optimal cost. The land type conversion results of the ecological service area in the main urban area of Chongqing are summarized in Table 6.

\section{$<$ Please insert Table 6 about here>}

After optimization of the landscape pattern, the landscape type distribution map of the main urban area of Chongqing was generated, as shown in Fig. 13.

\section{$<$ Please insert Fig. 13 about here>}

According to Table 6 and Fig.13, we could see the range of ecological nodes and the statistical results of landscape transformation. Among them, 14 cultivated land patches were converted into forest land, with a total area of $77.85 \mathrm{hm} 2,3$ cultivated land patches were converted into water area, with a total area of $12.22 \mathrm{hm} 2$, and 21 construction land patches were converted into forest land, with a total area of $105.57 \mathrm{hm} 2$. A total of 3 construction land patches were converted into water area, with a total area of $13.51 \mathrm{hm} 2$. All the land use patches converted into ecological land patches were $209.14 \mathrm{hm} 2$. The area of construction land converted to forest land is the largest, accounting for $50.48 \%$ of the total converted area. This is due to the spatial distribution of land use in the main urban area of Chongqing, the largest number and scale of forest land in the ecological land, the greatest possibility of nonecological land and forest land patches in the service area becoming the closest relationship, and the principle of optimal conversion cost. The optimized landscape pattern of the main urban area of Chongqing in 2015 was as follows: forest area accounts for $38.03 \%$, lawn area accounts for 
$0.27 \%$, water body accounts for $3.57 \%$, farmland area accounts for $20.16 \%$, unused land area accounts for $0.01 \%$, and cultivated land area accounts for $37.97 \%$.

\section{Discussion}

\subsection{Effectiveness evaluation of landscape ecological security pattern optimization}

The raster data of the land use types in the main urban areas of Chongqing after optimization and the raster data of the ecological land of Chongqing were imported into Fragstats 4.2 software to calculate the above landscape indicators. The results are listed in Table 7.

According to the landscape indicator calculation results of the ecological land before and after LESP optimization of the main urban areas of Chongqing, it is concluded that before and after LESP optimization, the proportion of the forest land patch area was the highest, covering $90.8423 \%$ and $90.8395 \%$ of the total area, respectively, and the proportion of the lawn patch area was the lowest, mainly based on the type of forest land patch, which was roughly the same as the landscape pattern in Chongqing. Compared with the data before optimization, the proportions of the forest land and lawn areas decreased slightly, while that of the water area increased slightly after optimization, but not significantly. PD of the forest land and water area increased, while PD of the lawn area remained unchanged. LPI decreased slightly, and FRAC of the forest land area increased, whereas the lawn area did not change, but the value for the water area decreased. In terms of SHDI, SHEI and CONTAG, the connectivity of landscape pattern of ecological land decreased insignificantly after optimization. Overall, the overall patch density of ecological land became better after optimization, although the overall value did not change much, it also indicated that the overall landscape structure of ecological land was less fragmented after optimization.

\section{$<$ Please insert Table 7 about here>}

Based on the calculation results of the landscape indicator based on land use and LESP optimization in the study area (Table 8), it is found that after LESP optimization, the percentage of forest land and water area had increased, while the lawn area percentage did not change. PD of the farmland area increased considerably, that of the lawn area remained unchanged, and that of the forest land and water area decreased and increased slightly, respectively. LPI remained basically constant, and the LSI indicator slightly increased. In terms of FRAC, that of the forest land area increased, that of the lawn area remained the same, and that of the water area decreased, which was consistent with the changes in ecological land. Regarding SHDI, SHEI and CONTAG, all values decreased slightly. In general, the overall numerical change in the land use landscape indicator was larger than that in the ecological land after optimization, and the land use ratio of the ecological land had clearly increased, indicating that optimization was effective and could provide a reference for actual applications.

$<$ Please insert Table 8 about here>

\subsection{Comparison of different landscape ecological security pattern}

The construction of landscape ecological security pattern is the foundation of regional ecological sustainable development, which plays a guiding role in spatial planning and orderly expansion of land use, and comes true the corresponding protection of important ecological source areas supporting regional environment. In the past researches, researchers conducted different degrees of reconstruction (Wang et al., 2019), assessment and optimization (Yu et al., 2018) on ecological source areas, ecological corridor (Hepcan et al., 2011), ecological nodes and network structure for different planning purposes. The main methods included MCR model, least-cost path models (Klar et al., 2012) to assess the importance of ecosystem services (Peng et al., 2018; Peng et al., 2019; Fu et al., 2020), coefficient of sensitivity (Gurrutxaga et al., 2011), ecological risk ( $\mathrm{Li}$ et al., 2020). Using patch aggregation and landscape connectivity to build ecological network (Aminzadeh et al., 2010), at the same time, integrating the fragmented landscape ecology in order to reshape and optimize the regional ecological security pattern. The structure results are different for different research contents, research purposes and research objects. Table 9 summed up the research results of different international scholars on the construction and optimization of ecological landscape, and the research methods are also different. We reviewed the relevant research on landscape ecological security pattern over the last ten years, concluded the study areas, research framework and research results. We found that there are no studies 
have been done to further optimize the reconstructed ecological pattern nodes, evaluate the effectiveness of the optimized ecological pattern from the perspective of landscape heterogeneity, and plan the overall layout of regional landscape from the perspective of land use. The granularity inverse method was used in this study, the best ecological landscape component structure of Chongqing urban area is selected by combining granularity and connectivity, which can provide an objective reference for the selection of other ecological sources. This method has more theoretical basis and objectivity than the traditional methods, and the principal component analysis method effectively avoided the subjectivity in the research. In this study, the optimal threshold of the optimal ecological node was determined, and the nearest neighbor principle and the optimal cost principle were adopted to provide a detailed practical basis for the accurate calculation of its shape and scale.

$<$ Please insert Table 9 about here $>$

\subsection{Research advantages and development proposals}

This study constructed the ecological security pattern scientifically and completely, including the scientific screening of ecological source areas, the construction of ecological resistance surface, and the identification of ecological corridors and ecological nodes. Different from the subjectivity and randomness of traditional ecological source selection, we chose methods with different regional applicability based on the granularity reverse method, which could provide reliable basis for ecological construction. In the construction of ecological resistance surface, we avoided the single consideration of the current situation of land use in the previous studies, and selected the ecological indicator factors which had strong correlation with the landscape ecological security process. The ecological resistance surface indicator factor system constructed was scientific, rigorous and practical. Combined with the special mountain structure in the study area, the identification of ecological corridors and nodes based on the minimum cumulative resistance surface was pertinence and operable; On the other hand, the content of landscape ecological security pattern optimization included two parts: landscape quantity and spatial structure optimization. There was no better optimization method to combine them in the present research results. Based on the microscale, this study constructed the ecological node service area, obtained the optimized land use spatial structure from the patch transformation idea of the ecological node service area, and carried on the quantitative analysis of the optimized landscape patch, which reflected this demand better. At the same time, the existing research scope of landscape ecological pattern was mostly large-scale area. However, with the increasing demand of human settlements for small and medium-sized urban areas, especially in the central urban areas, the contradiction between the ecological environment and urban construction in the central city needed to be solved. This research took Chongqing as an example to optimize the ecological pattern of landscape in small and medium scale, which could provide practical apply on other small and medium-sized areas; finally, the mountain city is different from other cities in geological structure, the ecological environment is relatively fragile, the ecological patches are more complex and special, there are forest patches in space along with the distribution characteristics of mountain structure, lawn patches are relatively small and so on. Chongqing is one of the most typical mountainous cities in China, which is located in the parallel ridge valley area of East Sichuan. In recent years, Chongqing has developed rapidly, the traffic construction land has expanded rapidly, and the fragmentation degree of urban ecological land has increased. Therefore, it is urgent to optimize the landscape ecological security pattern. This study took the main urban area of Chongqing as the research object, aiming at providing the optimization scheme of ecological security pattern with practical and scientific basis for ecological land planning of mountainous cities.

\section{Conclusions}

In this study, the main elements of landscape ecological security pattern of the main urban area of Chongqing, namely ecological source, ecological corridor and ecological node, were taken as the research object to construct the landscape ecological security pattern. On this basis, the optimization of urban landscape ecological pattern was studied and the optimization results were evaluated. In general, the proportion of ecological land increased significantly and the fragmentation of landscape decreased after optimization, which indicated that the optimization was effective and provided rational reference for urban landscape ecological planning. 
(1) Taking the ecological land in the main urban area of Chongqing as the research object, the ecological landscape types determined by the ecological benefit analysis are selected, and the ecological landscape component structure is generated according to different granularity. The landscape pattern indicator was selected from the perspective of overall connectivity by using the granularity reverse method and principal component analysis, and the landscape component structure of each granularity was analyzed. Finally, the overall landscape component with the best connectivity was obtained by scoring. $500 \mathrm{~m}$ was the most suitable reference for the selection of ecological source areas, and has the lowest degree of obstruction to the operation of ecological flow. (2) By constructing the single factor evaluation indicator system of ecological resistance and constructing the minimum cumulative resistance surface, the minimum cumulative resistance surface of landscape ecology in main urban area of Chongqing was divided into ecological buffer area, protection and utilization area, key development area, coordinated control area and restricted development area, accounting for $57.78 \%, 20.87 \%, 12.36 \%, 6.48 \%$ and $2.50 \%$ of the total area. (3) Taking the minimum cumulative consumption resistance surface as the cost surface of ecological flow operation, the ecological corridor and ecological node are constructed by using the hydrological analysis. There were 70 ecological corridors in the landscape ecological security pattern in the main urban area of Chongqing, with a total length of $415.89 \mathrm{~km}$. There were 17 ecological nodes of plateau type, namely corridor-resistance, and 27 are network strategic nodes, namely the ecological nodes of corridor-corridor. (4) Based on the analysis method of service area in network analysis, the radius of service area was calculated with reference to the granularity of optimal landscape components, and the shape and scale of service area of ecological node were obtained. The conversion principle of nonecological land in the service area of ecological node was the principle of nearest neighbor and the principle of optimal cost. The ecological nodes form 41 services, the total area was about $236.0723 \mathrm{hm}^{2}$, accounting for $0.04 \%$ of the main urban area of Chongqing. From the comparative analysis of landscape indicator, the optimized landscape pattern results could effectively improve the overall connectivity of the ecosystem and reduce the fragmentation degree of patches. The spatial distribution of these ecological key layout was affected by the current situation of land use and topography. It was shown that the spatial distribution of these ecological key layout was more evenly distributed in the central, southern and northern parted of the overall pattern, and presented a north-south zonal distribution, which showed the lack of planning of the main urban area of Chongqing and the ecological vulnerability as a typical mountain city.

\section{Ethical Approval}

All procedures performed in studies involving human participants were in accordance with the ethical standards of the institutional and/or national research committee.

\section{Consent to Participate}

Informed consent was obtained from all individual participants included in the study.

\section{Consent to Publish}

The manuscript is approved by all authors for publication.

\section{Authors Contributions}

G.D. and C.L. designed the study. J.Y. performed the analysis and prepared the manuscript. J.Y. and C.L. assembled input data, implemented the model and analyzed output data and results. C.L. conducted data collection and preliminary analysis. G.D. and C.L. revised the original manuscript. G.D. and J.Y. validated modelling results and discussed the results and implications. All authors participated in the writing of the manuscript.

\section{Funding information}

This work is partially sponsored by the Science and Technology Research Program of Chongqing Municipal Education Commission (No. KJZD-K201800702), the Ministry of education of Humanities and Social Science project (20YJA790016) and Natural Science Foundation of Chongqing in China (cstc2020jcyj-jq0004). 


\section{Competing Interests}

I would like to declare on behalf of my co-authors that the manuscript was original research that has not been published previously, and not under consideration for publication elsewhere, there is no conflict of interest exists in the submission.

\section{Availability of data and materials}

All data are processed by the author, true and effective, and all data generated or analysed during this study are included in this article.

\section{References}

Aminzadeh B, Khansefid M (2010) A case study of urban ecological networks and a sustainable city: Tehran's metropolitan area. Urban Ecosyst 13:23-36.

Abdullah SA, Nakagoshi N (2006) Changes in landscape spatial pattern in the highly developing state of Selangor, peninsular Malaysia. Landsc Urban Plan 77: 263-275.

Abdullah SA, Nakagoshi N (2008) Changes in agricultural landscape pattern and its spatial relationship with forestland in the State of Selangor, peninsular Malaysia. Landsc Urban Plan 87: 147-155.

Adriaensen F, Chardon JP, De Blust G, Swinnen E, Villalba S, Gulinck H, Matthysen E (2003) The application of "least-cost" modelling as a functional landscape model. Landsc Urban Plan 64: 233-247. https://doi.org/10.1016/S0169-2046(02)00242-6.

Chang H, Li F, Li ZG, Wang RS, Wang YL (2011) Urban landscape pattern design from the viewpoint of networks: A case study of Changzhou city in Southeast China. Ecol Complex 8: 51-59.

Dai L, Liu YB, Luo XY (2020) Integrating the MCR and DOI models to construct an ecological security network for the urban agglomeration around Poyang Lake, China. Sci Total Environ 754:141868. https://doi.org/10.1016/j.scitotenv.2020.141868.

Desmet PG (2018) Using landscape fragmentation thresholds to determine ecological process targets in systematic conservation plans. Biol Conserv 221: 257-260.

Evans CC, Moorhead AR, Storey BE, Blagburn BL, Wolstenholme AJ, Kaplan RM (2017) Evaluation of the larval migration inhibition assay for detecting macrocyclic lactone resistance in Dirofilaria immitis. Veterinary Parasitology 246: 6-81. http://doi.org/10.1016/j.vetpar.2017.09.003.

Falkmark M (2002) Human Livelihood Security Versus Ecological Security - An Ecohydrological Perspective. Proceedings, SIWI Seminar, Balancing Human Security and Ecological Security Interests in a Catchment - Towards Upstream/Downstream Hydrosolidarity. Stockholm, Sweden: Stockholm International Water Institute, 29-36

Folke C (2002) Entering Adaptive Manament And Resilience Into The Catchment Approach. Proceedings, SIWI seminar, Balancing Human Security and Ecological Security Interests in a Catchment - Towards Upstream/Downstream Hydrosolidarity. Stockholm, Sweden: Stockholm International Water Institute, 37-41.

Fu TJ, Shi XY, He J, Yuan Y, Qu LL (2020) Identification and optimization strategy of county ecological security pattern: A case study in the Loess Plateau, China. Ecol Indic 112: 106030.

Gao Y, Zhang CR, He QS, Liu YL (2017) Urban Ecological Security Simulation and Prediction Using an Improved Cellular Automata (CA) Approach-A Case Study for the City of Wuhan in China. Int. J. Environ. Res. Public Health 14(6): 643.

Geoffrey J, Matthews (2002) Hydrosolidarity - How To Link To The Economic Development Perspective. Proceedings, SIWI Seminar, Balancing Human Security and Ecological Security Interests in a Catchment - Towards Upstream/Downstream Hydrosolidarity. Stockholm, Sweden: Stockholm International Water Institute, 42-51.

Gurrutxaga M, Rubio L, Saura S (2011) Key connectors in protected forest area networks and the impact of highways: A transnational case study from the Cantabrian Range to the Western Alps (SW Europe). Landsc Urban Plan 101: 310-320.

Hepcan CC, Özkan MB (2011) Establishing ecological networks for habitat conservation in the case of Çe, sme-Urla Peninsula, Turkey. Environ Monit Assess 174:157-170.

Jia YQ, Tang LN, Xu M, Yang XY (2019) Landscape pattern indices for evaluating urban spatial morphology - A case study of Chinese cities. Ecol Indic 99(APR.): 27-37. https://doi.org/10.1016/j.ecolind.2018.12.007.

Jiang W, Cai Y, Tian J (2019) The application of minimum cumulative resistance model in the evaluation of urban 
ecological land use efficiency. Arab J Geosci 12(23): 1-7.

Jim C, Chen S (2003) Comprehensive greenspace planning based on landscape ecology principles in compact Nanjing City, China. Landsc Urban Plan 65(3): 95-116.

Johnson RA, Wichern DW (1998) Applied Multivariate Statistical Analysis. 4th ed.; Englewood Cliffs: Prentice-hall, Inc. Junqueira VS, Cardoso FF, Oliveira MM, Sollero BP, Silva FF, Lopes PS (2017) Use of molecular markers to improve relationship information in the genetic evaluation of beef cattle tick resistance under pedigree-based models. J Anim Breed Genet 134(1): 14

Klar N, Herrmann M, Henning-Hahn M, Pott-Dörfer B, Hofer H, Kramer-Schadt S (2012) Between ecological theory and planning practice: (Re-) Connecting forest patches for the wildcat in Lower Saxony, Germany. Landsc Urban Plan 105: 376-384.

Knaapen JP, Scheffer M, Harms B (1992) Estimating habitat isolation in landscape planning. Lands Urban Plan 23(1): 1-16.

Liang J, He XY, Zeng GM, Zhong MZ, Gao X, Li X, Li XD, Wu HP, Feng CT, Xing WL, Fang YL, Mo D (2018) Integrating priority areas and ecological corridors into national network for conservation planning in China. Sci Total Environ 626: 22-29. https://doi.org/10.1016/j.scitotenv.2018.01.086.

Li SC, Xiao W, Zhao YL, Lv XJ (2020) Incorporating ecological risk index in the multi-process MCRE model to optimize the ecological security pattern in a semi-arid area with intensive coal mining: A case study in northern China. J Clean Prod 247: 119143.

Liu R, Shen Z (2007) Integrated assessment and changes of ecological environment in the Daning River Watershed. Frontiers of Biology in China 2(4): 474-478. http://doi.org/10.1007/s11515-007-0072-9.

Li F, Ye Y, Song B, Wang R (2015) Evaluation of urban suitable ecological land based on the minimum cumulative resistance model: A case study from Changzhou, China. Ecol Modell 318: 194-203. http://doi.org/10.1016/j.ecolmodel.2014.09.002.

Li ZT, Li M, Xia BC (2020) Spatio-temporal dynamics of ecological security pattern of the Pearl River Delta urban agglomeration based on LUCC simulation. Ecol Indic 114: 106319.

Li ZX, Xu LY (2010) Evaluation indicators for urban ecological security based on ecological network analysis. Pro Environ Sci 2: 1393-1399.

López S, López-Sandoval MF, Gerique A, Salazar J (2020) Landscape change in Southern Ecuador: An indicator-based and multitemporal evaluation of land use and land cover in a mixed-use protected area. Ecol Indic 115: 106357.

Lu SS, Tang X, Guan XL, Qin F, Liu X, Zhang DH (2020) The assessment of forest ecological security and its determining indicators: A case study of the Yangtze River Economic Belt in China. J Environ Manag 258: 110048.

Ma LB, Bo J, Li XY, Fang F, Cheng WJ (2019) Identifying key landscape pattern indices influencing the ecological security of inland river basin: The middle and lower reaches of Shule River Basin as an example. Sci Total Environ 674: 424-438.

Mayer AL, Buma B, Davis A, Gagné SA, Loudermilk EL, Scheller RM, Schmirgrlow FKA, Wiersma YF, Franklin J (2016) How landscape ecology informs global land-change science and policy. Bioscience 66(6): 485-469. https://doi.org/10.1093/biosci/biw035.

Mõisja K, Uuemaa E, Oja T (2016) Integrating small-scale landscape elements into land use/cover: The impact on landscape metrics' values. Ecol Indic 67: 714-722.

Molden D (2002) Balancing Human Livelihood Security and Ecological Security in a Catchment - Towards Upstream/Downstream Hydrosolidarity. Stockholm, Sweden: Stockholm International Water Institute, 14-28.

Monaco R, Negrini G, Salizzoni E, Soares AJ, Voghera A (2020) Inside-outside park planning: A mathematical approach to assess and support the design of ecological connectivity between Protected Areas and the surrounding landscape. Ecol Eng 149: 105748.

Mo WB, Wang Y, Zhang YX, Zhuang DF (2017) Impacts of road network expansion on landscape ecological risk in a megacity, China: a case study of Beijing. Article Sci Total Environ 574: 1000-1011.

Opdam P, Steingröver E, Rooij SV (2006) Ecological networks: A spatial concept for multi-actor planning of sustainable landscapes. Landsc Urban Plan 75: 322-332.

Pan JH, Wang Y (2019) Building ecological security patterns based on ecosystem services value reconstruction in an arid inland basin: A case study in Ganzhou District, NW China. J Clean Prod 241: 118337.

Peng J, Pan YJ, Liu YX, Zhao HJ, Wang YL (2018) Linking ecological degradation risk to identify ecological security patterns in a rapidly urbanizing landscape. Habitat Int 71: 110-124.

Peng J, Zhao MY, Guo XN, Pan YJ, Liu YX (2017) Spatial-temporal dynamics and associated driving forces of urban ecological land: A case study in Shenzhen City, China. Habitat Int 60: 81-90.

Peng J, Zhao SQ, Dong JQ, Liu YX, Meersmans J, Li HL, Wu JS (2019) Applying ant colony algorithm to identify ecological security patterns in megacities. Environ Modell Softw 117: 214-222.

Peng J, Yang J, Liu YX, Hu YN, Du YY, Meersmans J, Qiu SJ (2018) Linking ecosystem services and circuit theory to identify ecological security patterns. Sci Total Environ 644: 781-790. 
Peng J, Wang YL, Zhang Y, Wu JS, Li WF, Li Y (2010) Evaluating the effectiveness of landscape metrics in quantifying spatial patterns. Ecol Indic 10(2): 217-223.

Pili S, Serra P, Salvati L (2019) Landscape and the city: Agro-forest systems, land fragmentation and the ecological network in Rome, Italy. Urban For Urban Green 41: 230-237.

Rajagopal A (2002) Balancing Upstream Agriculture Security With Downstream Aquaculture 'Prosperity' - Some Reflections From India. Proceedings, SIWI seminar, Balancing Human Security and Ecological Security Interests in a Catchment - Towards Upstream/Downstream Hydrosolidarity. Stockholm, Sweden: Stockholm International Water Institute, 61-64.

Saura S, Rubio L (2010) A common currency for the different ways in which patches and links can contribute to habitat availability and connectivity in the landscape. Ecography 33: 523-537. https://doi.org/10.1111/j.1600-0587.2009.05760.x.

Sendama A, Granit J (2002) A New Approach to The Joint Management of River Basins In The Lake Victoria Basin. Proceedings, SIWI seminar, Balancing Human Security and Ecological Security Interests in a Catchment - Towards Upstream/Downstream Hydrosolidarity. Stockholm, Sweden: Stockholm International Water Institute, 65-71.

Shi FN, Liu SL, Sun YX, An Y, Zhao S, Liu YX, Li MQ (2020) Ecological network construction of the heterogeneous agro-pastoral areas in the upper Yellow River basin. Agri Ecosyst Envir 302: 107069. https://doi.org/10.1016/j.agee.2020.107069.

Sunderland T, Abdoulaye R, Ahammad R, Asaha S, Baudron F, Deakin E, Duriaux JY, Eddy I, Foli S, Gumbo D, Khatunl K, Kondwani M, Kshatriya M, Leonald L, Rowland D, Stacey N, Tomscha S, Yang K, Gergel S, Vianen JV (2017) A methodological approach for assessing cross-site landscape change: Understanding socio-ecological systems. Forest Policy Econ 84: 83-91.

Su K, Yu QA, Yue DP, Zhang QB, Yang L, Liu ZL, Niu T, Sun XT (2019) Simulation of a forest-grass ecological network in a typical desert oasis based on multiple scenes. Ecol Modell 413: 108834.

Su YX, Chen XZ, Liao JS, Zhang HG, Wang CJ, Ye YY, Wang Y (2016) Modeling the optimal ecological security pattern for guiding the urban constructed land expansions. Urban For. Urban Green. 19: 35-46. https://doi.org/10.1016/j.ufug.2016.06.013.

Teng MJ, Wu CG, Zhou ZX, Lord E, Zheng ZM (2011) Multipurpose greenway planning for changing cities: a framework integrating priorities and a least-cost path model. Landsc Urban Plan 103: 1-14. https://doi.org/10.1016/j.landurbplan.2011.05.007.

Turner MG (2005) "LANDSCAPE ECOLOGY: What Is the State of the Science?." Annu Rev Ecol Evol S 36: 319-344.

Wang S, Wu MQ, Hu MM, Chen F, Wang T, Xia BC (2021) Promoting landscape connectivity of highly urbanized area: An ecological network approach. Ecol Indic 125: 107487. https://doi.org/10.1016/j.ecolind.2021.107487.

Wang Y, Ding Q, Zhuang DF (2015) An eco-city evaluation method based on spatial analysis technology: A case study of Jiangsu Province, China. Ecol Indic 58: 37-46.

Wang Y, Pan JH (2019) Building ecological security patterns based on ecosystem services value reconstruction in an arid inland basin: A case study in Ganzhou District, NW China. J Clean Pro 241: 118337.

Wang CR, Liu HX (2020) Developing large-scale international ecological networks based on least-cost path analysis - a case study of Altai mountains. Open Geosci 12(1): 840-850. https://doi.org/10.1515/geo-2020-0173.

Wang CX, Yu CY, Chen TQ, Feng Z, Hu YC, Wu LN (2020) Can the establishment of ecological security patterns improve ecological protection? An example of Nanchang, China. Sci Total Environ 740: 140051. https://doi.org/10.1016/j.scitotenv.2020.140051.

Weber T, Sloan A, Wolf J (2006) Maryland's green infrastructure assessment: Development of a comprehensive approach to land conservation. Landsc Urban Plan 77: 94-110.

Xie HL, Yao GR, Liu GY (2015) Spatial evaluation of the ecological importance based on GIS for environmental management: A case study in Xingguo county of China. Ecol Indic 51: 3-12.

Ye YY, Su YX, Zhang HO, Wu Q, Liu K (2015) Ecological resistance surface model and its application in urban expansion simulations. Acta Geographica Sinica. 04: 485-496. (in Chinese).

Yu KJ (1996) Security patterns and surface model in landscape ecological planning. Landsc Urban Plan 36(1): 1-17. https://doi.org/10.1016/S0169-2046(96)00331-3.

Yu QA, Yue DP, Wang JP, Zhang QB, Li YT, Yu Y, Chen JX, Li N (2017) The optimization of urban ecological infrastructure network based on the changes of county landscape patterns: a typical case study of ecological fragile zone located at Deng Kou (Inner Mongolia). J Clean Prod 163: S54-S67.

Yu QA, Yue DP, Wang YH, Kai S, Fang MZ, Ma H, Zhang QB, Huang Y (2018) Optimization of ecological node layout and stability analysis of ecological network in desert oasis: a typical case study of ecological fragile zone located at Deng Kou County (Inner Mongolia). Ecol Indic 84: 304-318.

Zhang LQ, Peng J, Liu YX, Wu JS (2017) Coupling ecosystem services supply and human ecological demand to identify 
landscape ecological security pattern: A case study in Beijing-Tianjin-Hebei region, China. Urban Ecosyst 20(3):

701-714. https://doi.org/10.1007/s11252-016-0629-y.

Zhao SM, Ma YF, Wang JL, You XY (2019) Landscape Pattern Analysis and Ecological Network Planning of Tianjin City. Urban For Urban Green 46: 126479.

Zhao XQ, Xu XH (2015) Research on Landscape Ecological Security Pattern in a Eucalyptus Introduced Region Based on Biodiversity Conservation. Russ J Ecol 46: 59-70. 


\section{Figures}

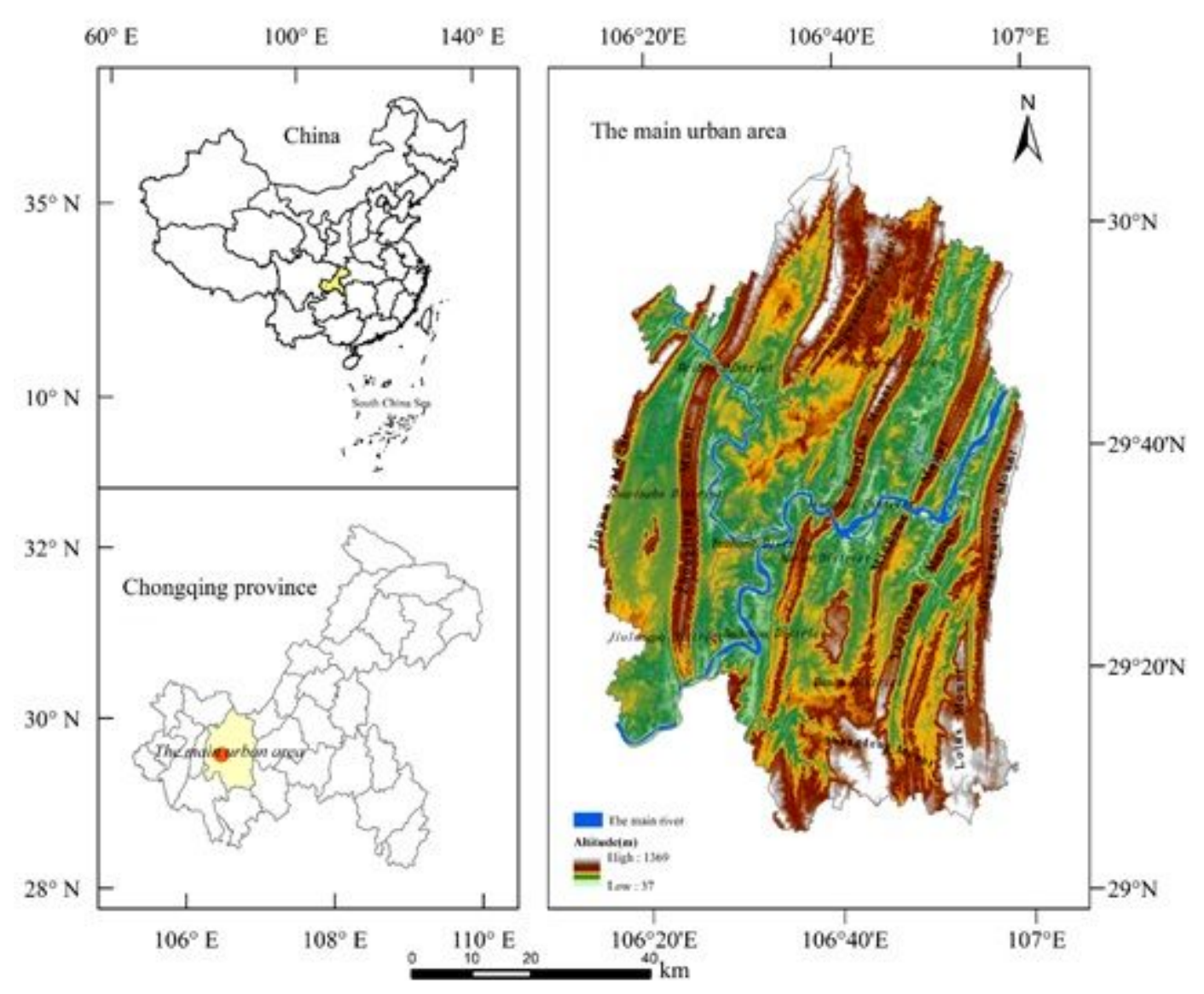

Figure 1

Location of the main urban area with main nature environment information in Chongqing, China. Note: The designations employed and the presentation of the material on this map do not imply the expression of any opinion whatsoever on the part of Research Square concerning the legal status of any country, territory, city or area or of its authorities, or concerning the delimitation of its frontiers or boundaries. This map has been provided by the authors. 


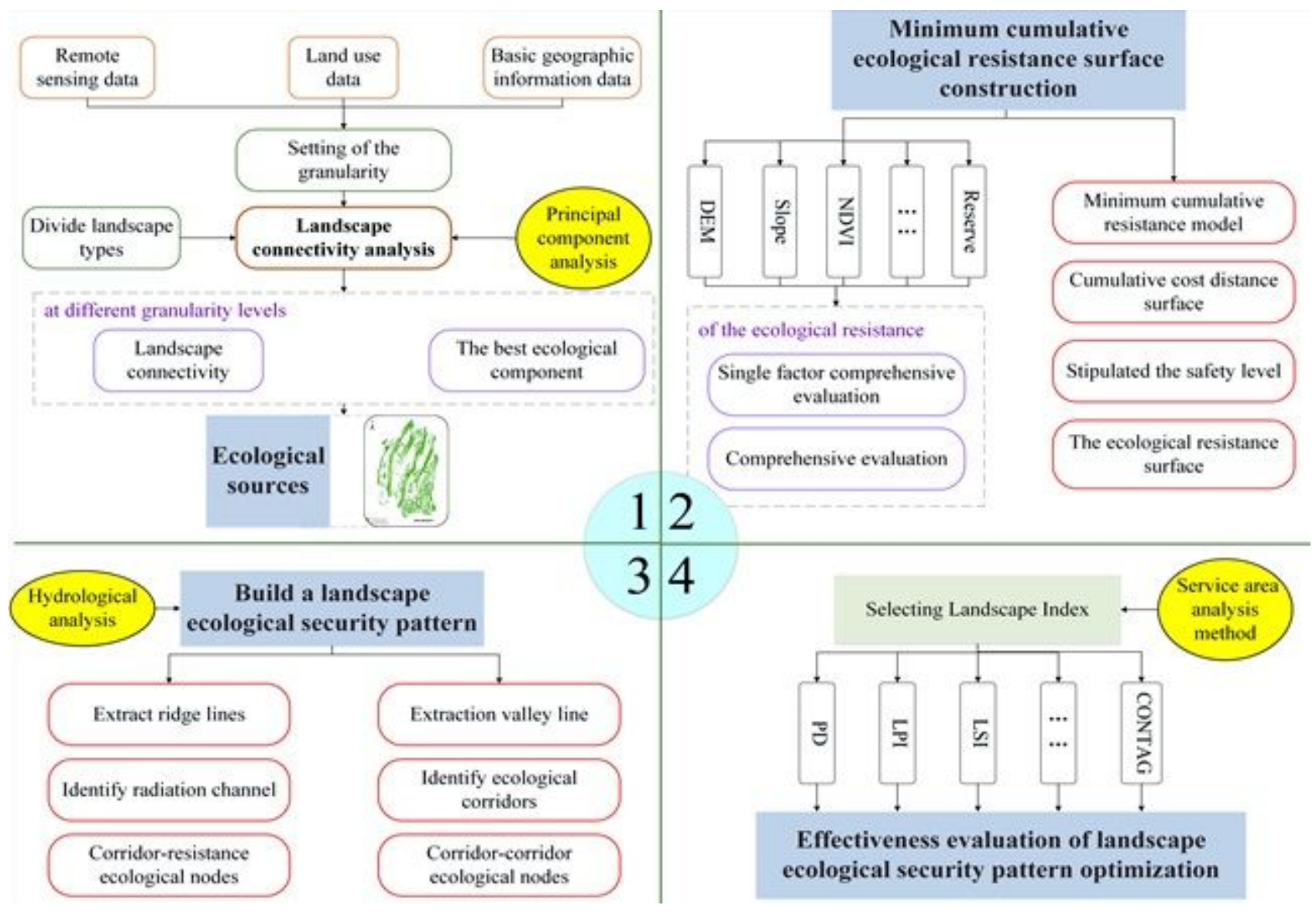

\section{Figure 2}

The research flows 


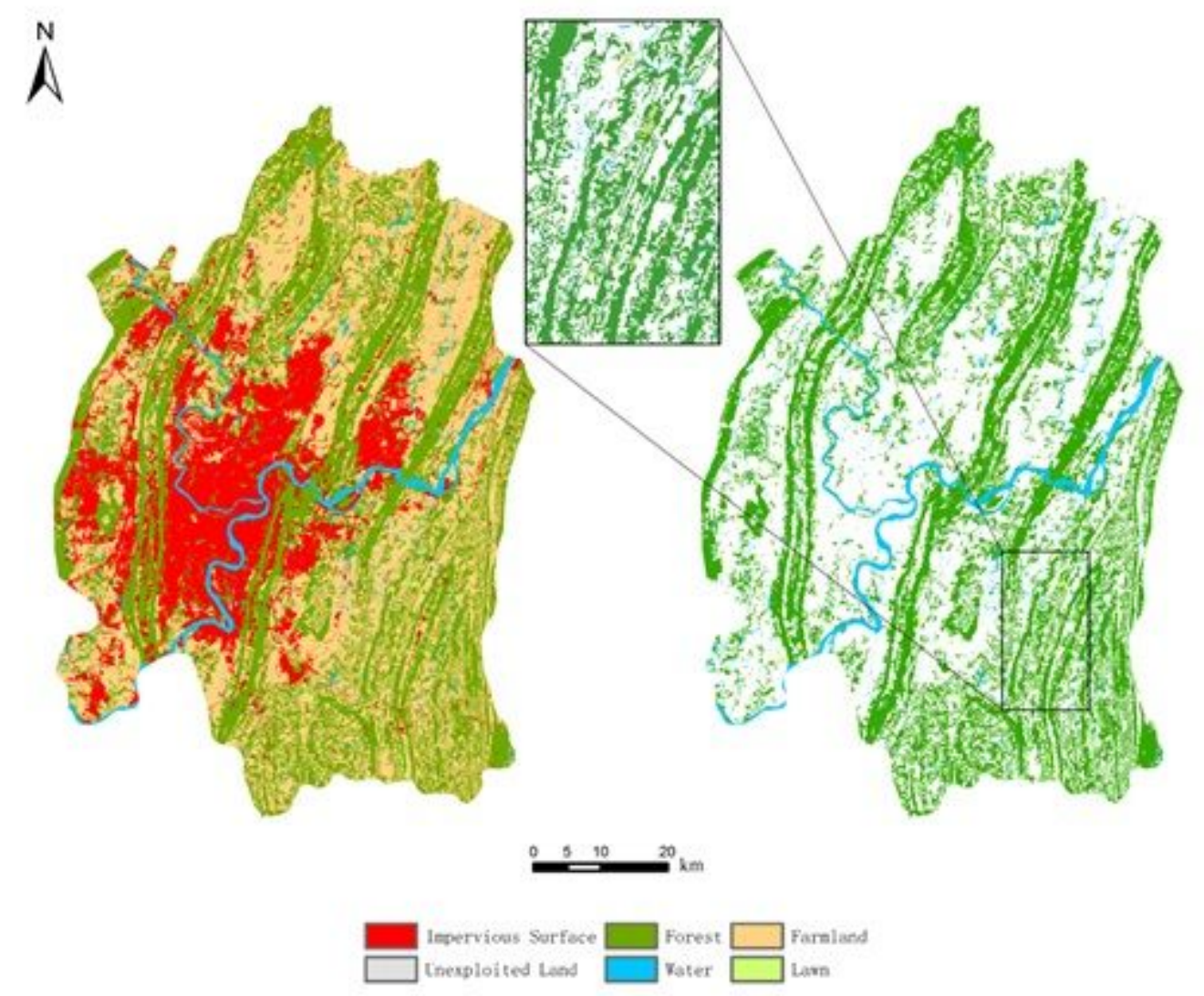

Figure 3

Land use and ecological land of the main urban area in Chongqing. Note: The designations employed and the presentation of the material on this map do not imply the expression of any opinion whatsoever on the part of Research Square concerning the legal status of any country, territory, city or area or of its authorities, or concerning the delimitation of its frontiers or boundaries. This map has been provided by the authors. 

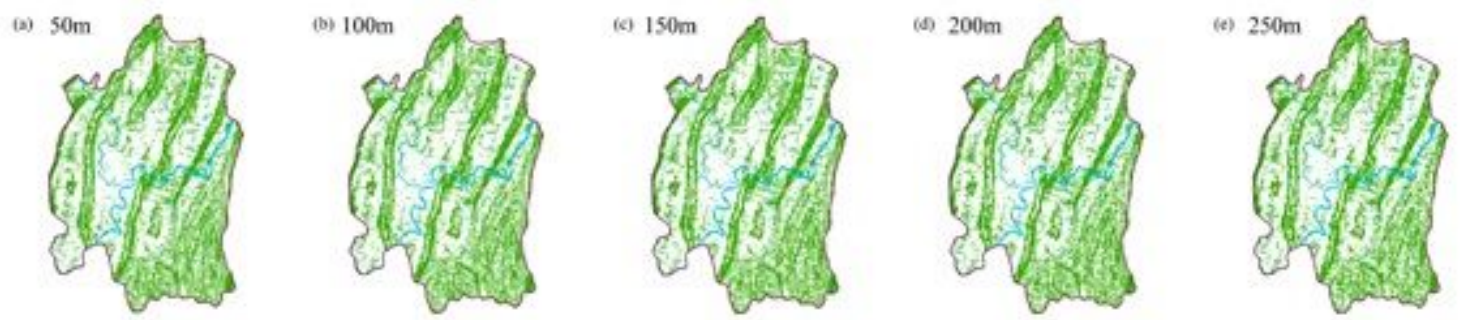

(6) $300 \mathrm{~m}$
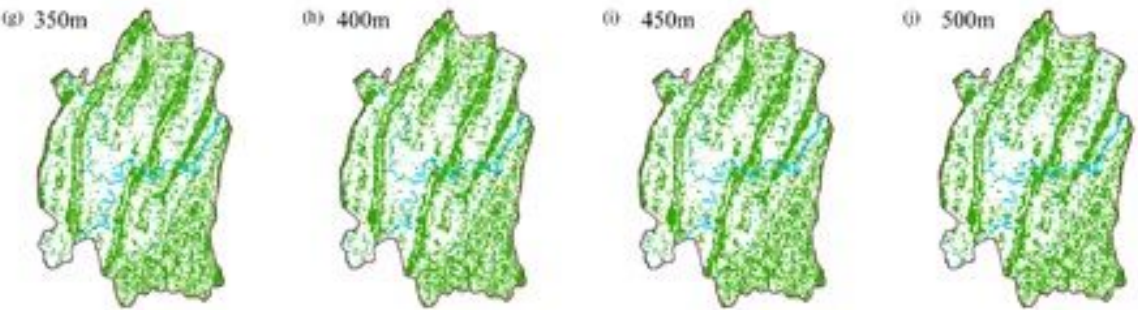

(a) $550 \mathrm{~m}$

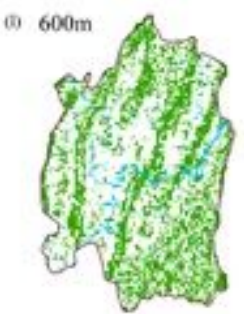

(m) $700 \mathrm{~m}$

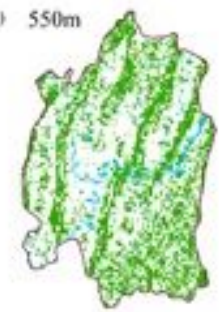

(p) $1000 \mathrm{~m}$

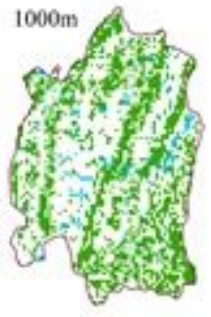

(4) $1100 \mathrm{~m}$
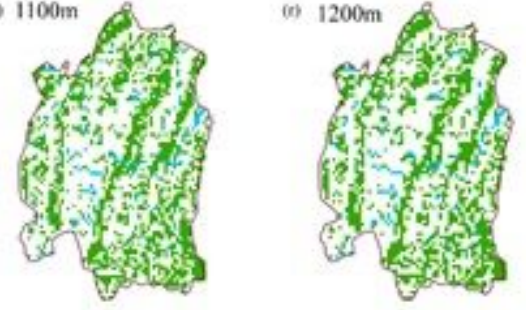

(a) $800 \mathrm{~m}$
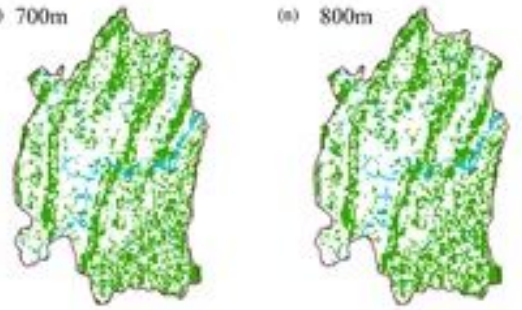

(क) $900 \mathrm{~m}$
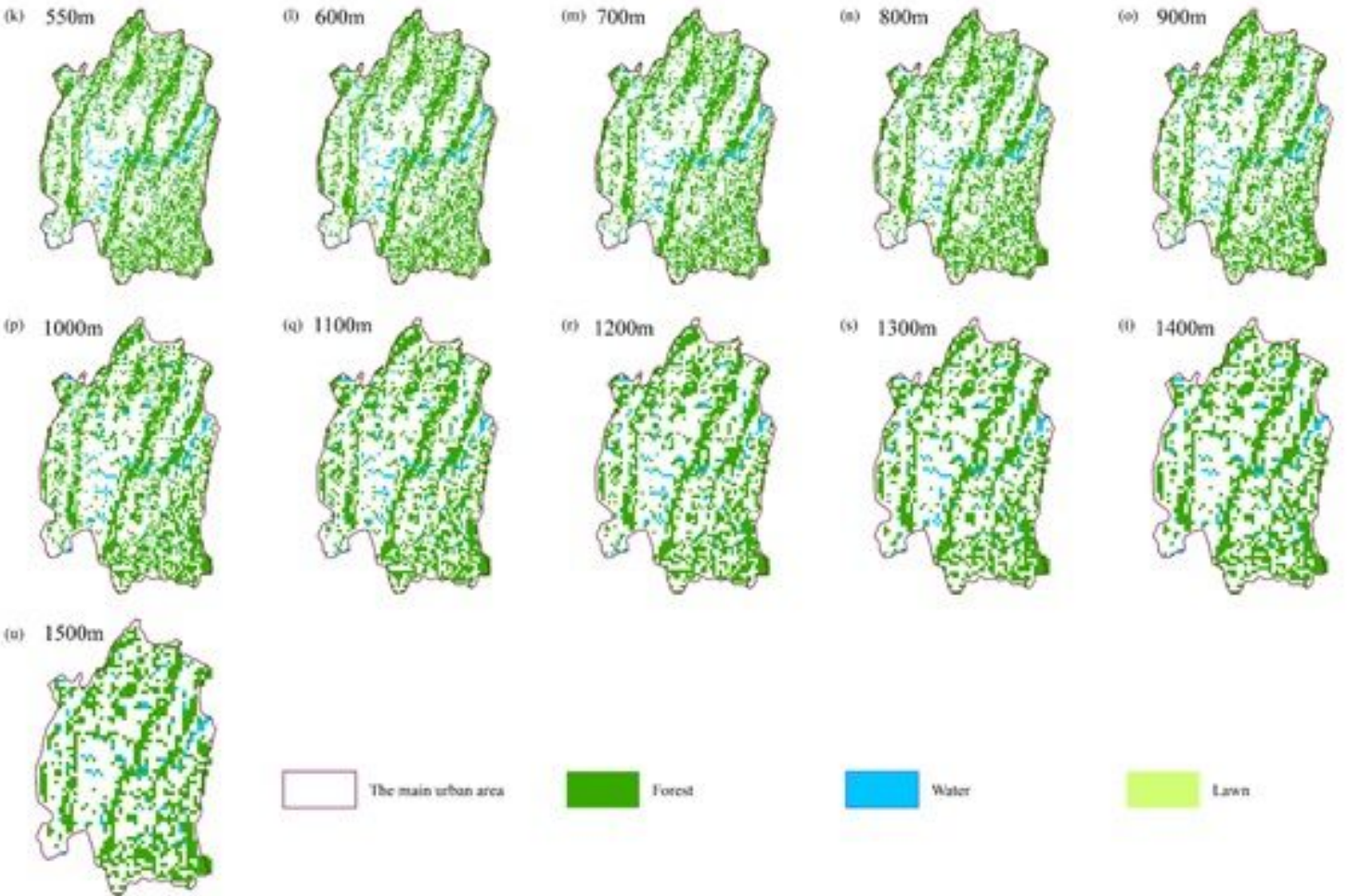

Figure 4

Different granularity of ecological land of the main urban area in Chongqing. Note: The designations employed and the presentation of the material on this map do not imply the expression of any opinion whatsoever on the part of Research Square concerning the legal status of any country, territory, city or area or of its authorities, or concerning the delimitation of its frontiers or boundaries. This map has been provided by the authors. 

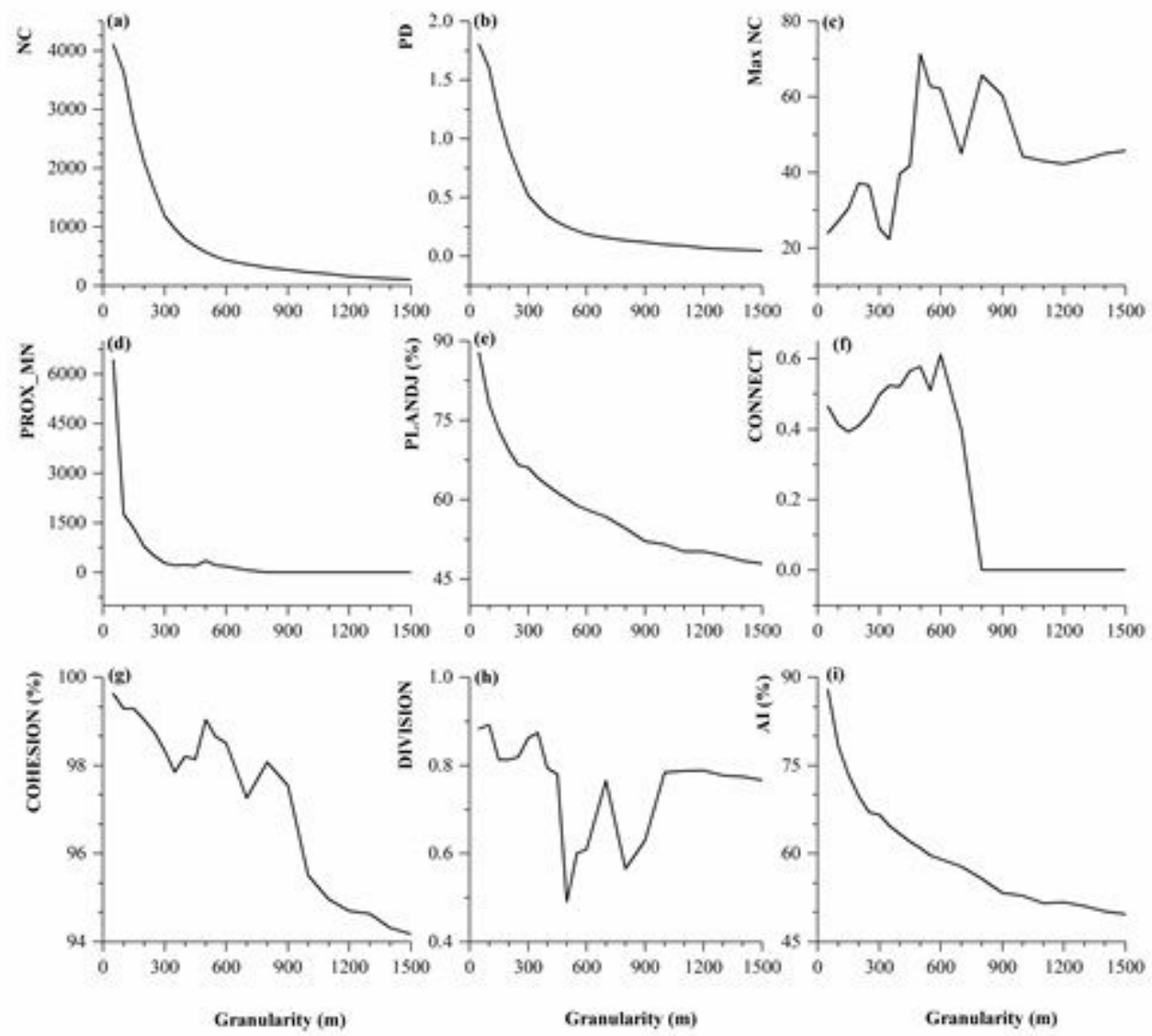

Figure 5

A series landscape index for different gains of ecological land

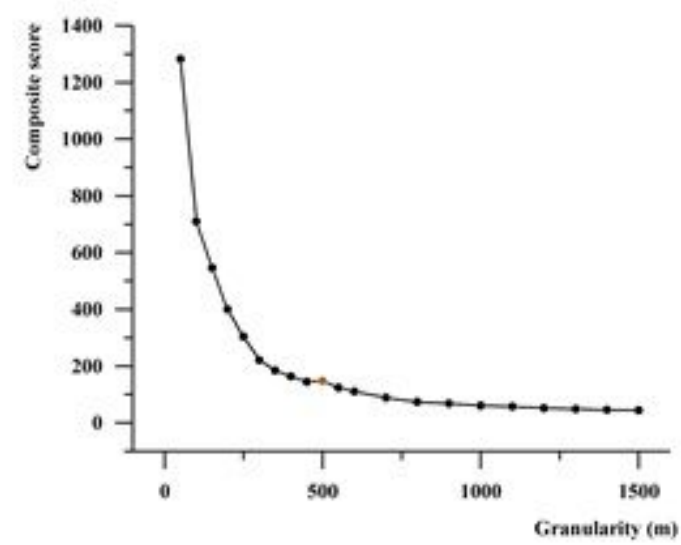

Figure 6

Composite score of a series landscape index for different gains of ecological land 


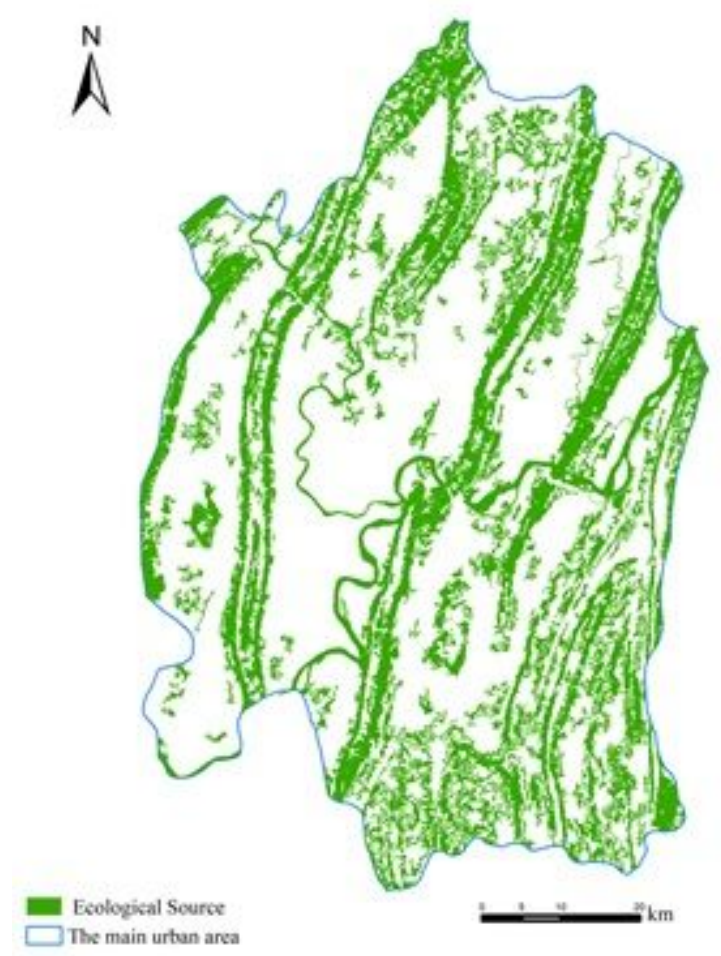

Figure 7

Ecological sources of the main urban area in Chongqing. Note: The designations employed and the presentation of the material on this map do not imply the expression of any opinion whatsoever on the part of Research Square concerning the legal status of any country, territory, city or area or of its authorities, or concerning the delimitation of its frontiers or boundaries. This map has been provided by the authors. 

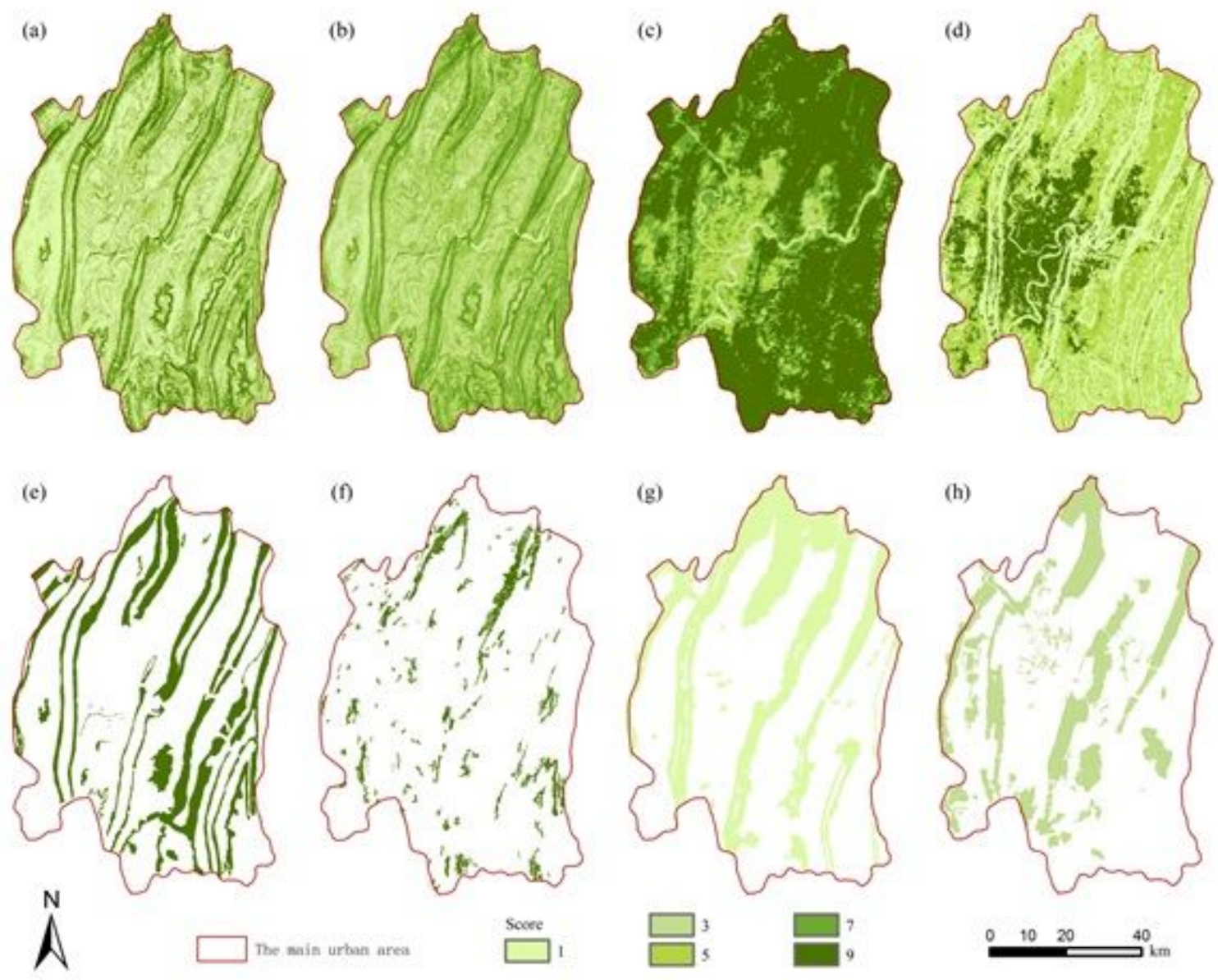

\section{Figure 8}

Single evaluation result of every ecological resistance of the main urban area in Chongqing. Note: The designations employed and the presentation of the material on this map do not imply the expression of any opinion whatsoever on the part of Research Square concerning the legal status of any country, territory, city or area or of its authorities, or concerning the delimitation of its frontiers or boundaries. This map has been provided by the authors. 

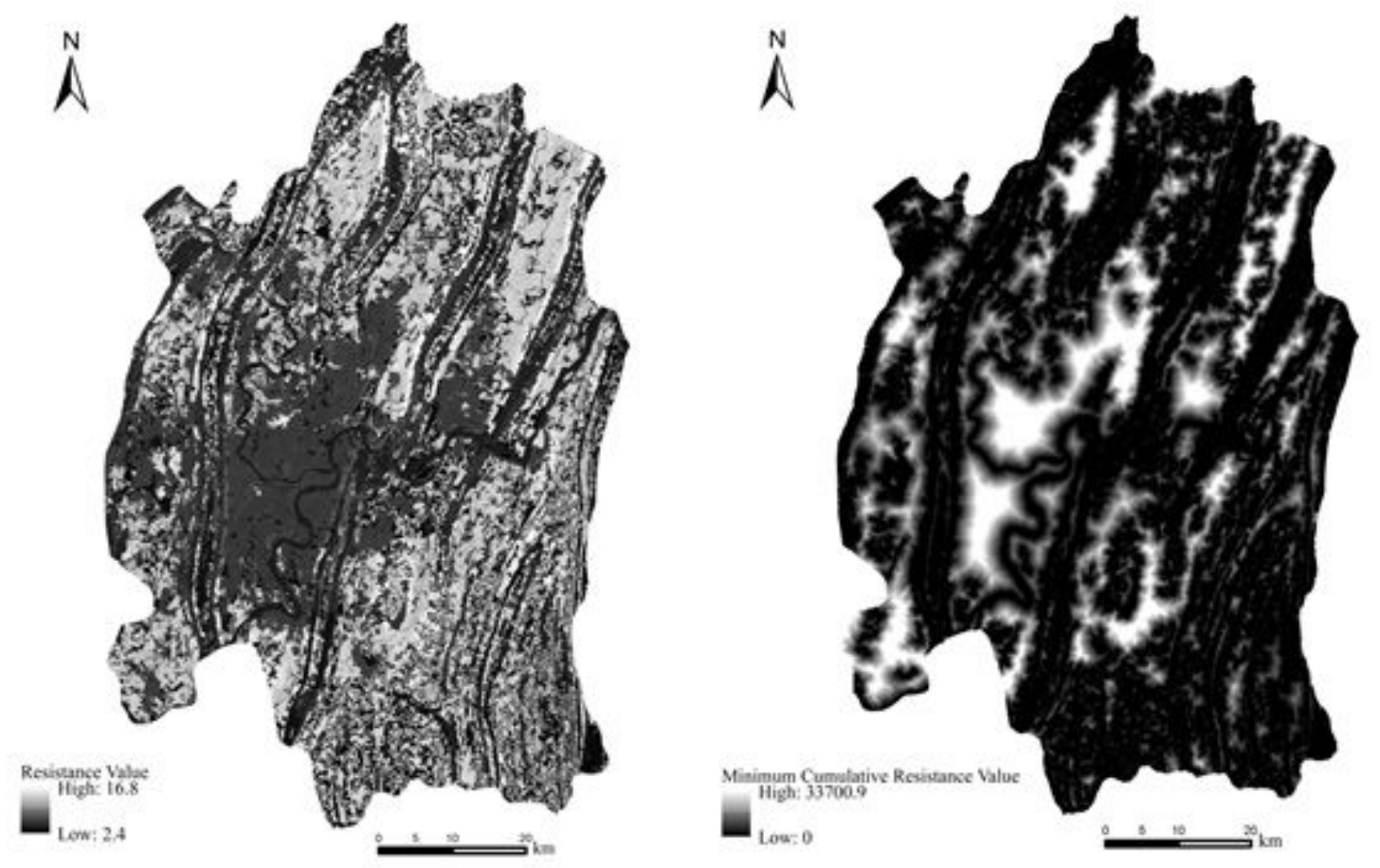

Figure 9

Evaluation result of ecological resistance and minimal cumulative resistance of the main urban area in Chongqing. Note: The designations employed and the presentation of the material on this map do not imply the expression of any opinion whatsoever on the part of Research Square concerning the legal status of any country, territory, city or area or of its authorities, or concerning the delimitation of its frontiers or boundaries. This map has been provided by the authors. 


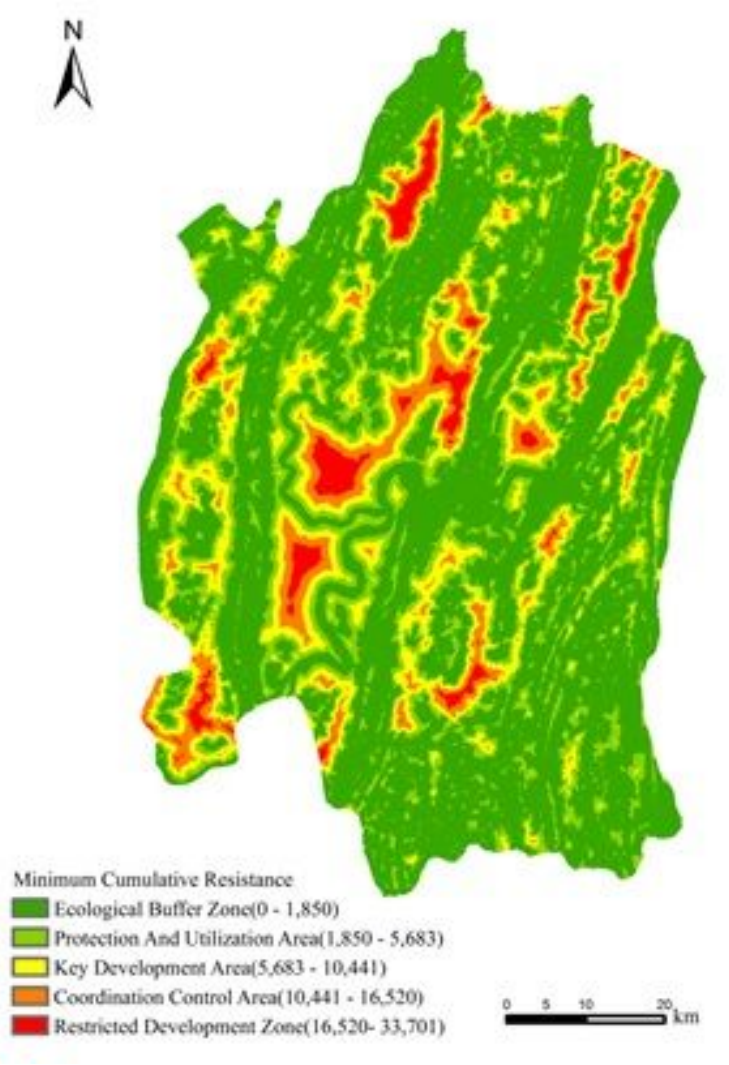

Figure 10

Different functional zones of MCR for the ecological landscape of the main urban area in Chongqing. Note: The designations employed and the presentation of the material on this map do not imply the expression of any opinion whatsoever on the part of Research Square concerning the legal status of any country, territory, city or area or of its authorities, or concerning the delimitation of its frontiers or boundaries. This map has been provided by the authors. 


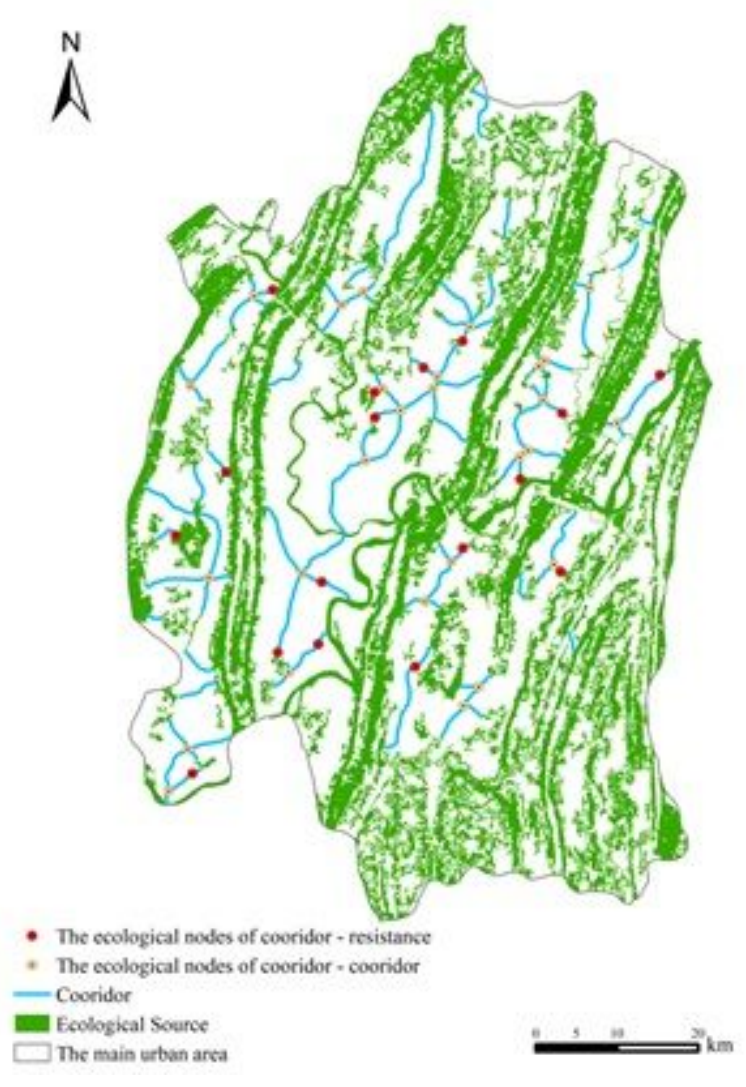

\section{Figure 11}

Landscape ecological security pattern of the main urban area in Chongqing. Note: The designations employed and the presentation of the material on this map do not imply the expression of any opinion whatsoever on the part of Research Square concerning the legal status of any country, territory, city or area or of its authorities, or concerning the delimitation of its frontiers or boundaries. This map has been provided by the authors. 


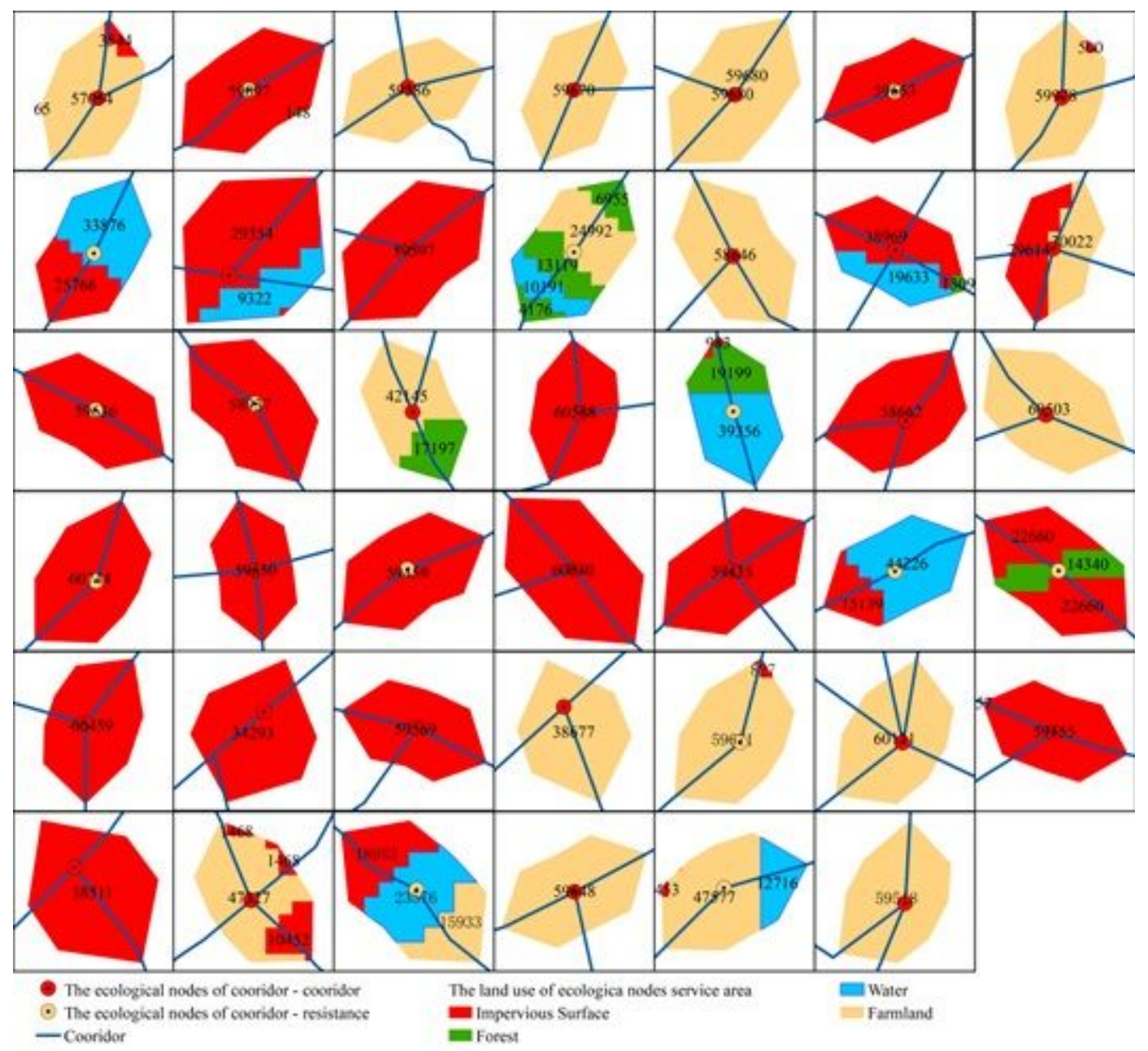

Figure 12

Service area of ecological nodes of the main urban area in Chongqing. Note: The designations employed and the presentation of the material on this map do not imply the expression of any opinion whatsoever on the part of Research Square concerning the legal status of any country, territory, city or area or of its authorities, or concerning the delimitation of its frontiers or boundaries. This map has been provided by the authors. 


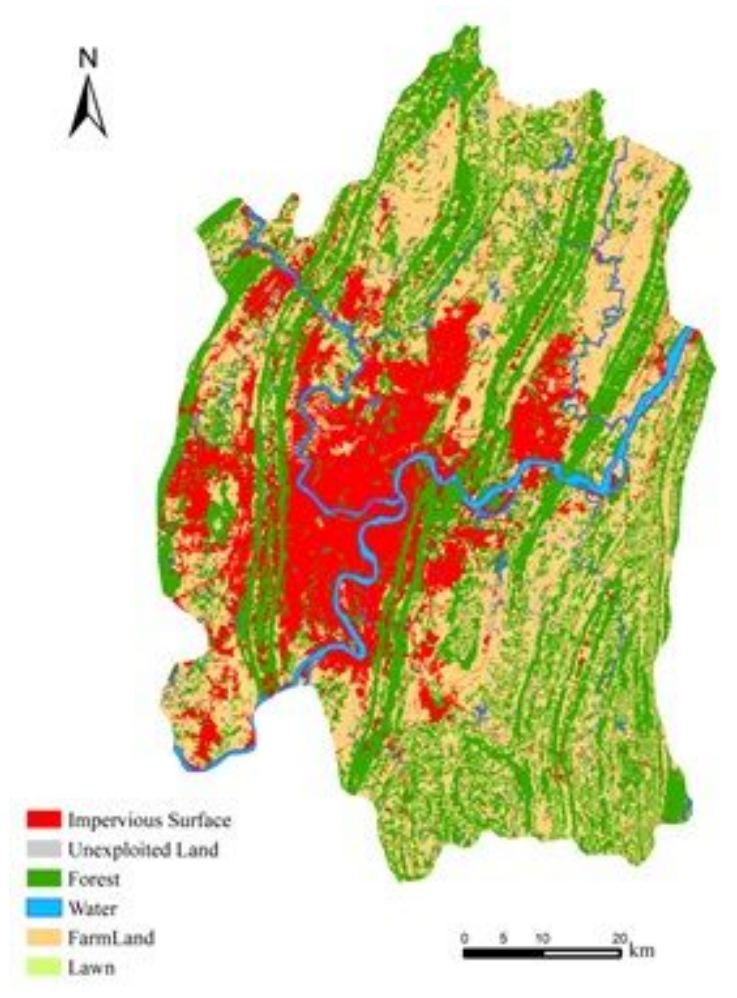

\section{Figure 13}

Land use of the main urban area in Chongqing after landscape security pattern optimization. Note: The designations employed and the presentation of the material on this map do not imply the expression of any opinion whatsoever on the part of Research Square concerning the legal status of any country, territory, city or area or of its authorities, or concerning the delimitation of its frontiers or boundaries. This map has been provided by the authors.

\section{Supplementary Files}

This is a list of supplementary files associated with this preprint. Click to download.

- Tablecaptions.pdf 